CONTRACTOR REPORT

SAND96-1088

Unlimited Release

UC-603

F

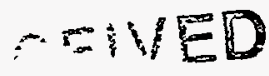

MAY 151996

OSTI

Phase II Report on the

\title{
Evaluation of Polyacrylonitrile (PAN) \\ as a Binding Polymer for Absorbers \\ Used to Treat Liquid Radioactive Wastes
}

Ferdinand Šebesta, Jan John, Alois Motl

Faculty of Nuclear Sciences and Physical Engineering

Department of Nuclear Chemistry

Czech Technical University in Prague

Břehová 7, CS - 11519 Prague 1, Czech Republic

Prepared by

Sandia National Laboratories

Albuquerque, New Mexico 87185 and Livermore, Califomia 94550

for the United States Department of Energy

under Contract DE-ACO4-94AL85000

Approved for public release; distribution is unlimited.

Printed May 1996 
Issued by Sandia National Laboratories, operated for the United States Department of Energy by Sandia Corporation.

NOTICE: This report was prepared as an account of work sponsored by an agency of the United States Government. Neither the United States Government nor any agency thereof, nor any of their employees, nor any of their contractors, subcontractors, or their employees, makes any warranty, express or implied, or assumes any legal liablity or responsibility for the accuracy, completeness, or usefulness of any information, apparatus, product, or process disclosed, or represents that its use would not infringe privately owned rights. Reference herein to any specific commercial product, process, or service by trade name, trademark, manufacturer, or otherwise, does not necessarily constitute or imply its endorsement, recommendation, or favoring by the United States Government, any agency thereof or any of their contractors or subcontractors. The views and opinions expressed herein do not necessarily state or reflect those of the United States Government, any agency thereof or any of their contractors.

Printed in the United States of America. This report has been reproduced directly from the best available copy.

Available to DOE and DOE contractors from Office of Scientific and Technical Information PO Box 62

Oak Ridge, TN 37831

Prices available from (615) 576-8401, FTS 626-8401

Available to the public from

National Technical Information Service

US Department of Commerce

5285 Port Royal RD

Springfield, VA 22161

NTIS price codes

Printed copy: A03

Microfiche copy: A01 


\title{
Phase II Report on the Evaluation of Polyacrylonitrile (PAN) as a Binding Polymer for Absorbers Used to Treat Liquid Radioactive Wastes
}

\author{
Ferdinand Šebesta, Jan John, Alois Motl \\ Faculty of Nuclear Sciences and Physical Engineering \\ Department of Nuclear Chemistry \\ Czech Technical University in Prague \\ Břehová 7, CS - 11519 Prague 1, Czech Republic
}

\begin{abstract}
The performance of polyacrylonitrile (PAN)-based composite absorbers was evaluated in dynamic experiments at flow rates ranging from 25 to 100 bed volumes (BV) per hour. Composite absorbers with active components of ammonium molybdophosphate (AMP) PAN and potassiumcobalt ferrocyanide (KCoFC) PAN were used for separating cesium from a $1 M \mathrm{HNO}_{3}+1 M$ $\mathrm{NaNO}_{3}+2 \times 10^{-5} \mathrm{MCsCl}$ acidic simulant solution. KCoFC-PAN and two other ferrocyanidebased composite absorbers were tested for separating cesium from alkaline simulant solutions containing $0.01 \mathrm{M}$ to $1 \mathrm{MNaOH}$ and $1 \mathrm{MNaNO}_{3}+2 \times 10^{-4} \mathrm{M} \mathrm{CsCl}$. The efficiency of the cesium sorption on the AMP-PAN absorber from acidic simulant solutions was negatively influenced by the dissolution of the AMP active component. At flow rates of $\sim 50 \mathrm{BV} / \mathrm{hr}$, the decontamination factor $D_{f} \sim 10^{3}$ could be maintained for treatment of $\sim 380 \mathrm{BV}$ of the feed. With the KCoFCPAN absorber, the decontamination factor $D_{f} \sim 10^{3}$ could be maintained for a feed volume as great as $1800 \mathrm{BV}$. In alkaline simulant solutions, significant decomposition of the active components was observed, and the best performance was exhibited by the KCoFC-PAN absorber. The efficiency of cesium separation from the simulant containing $0.01 \mathrm{M} \mathrm{NaOH}$ at a flow rate of $50 \mathrm{BV} / \mathrm{hr}$ was comparable to that found for acidic simulant solutions. At higher $\mathrm{NaOH}$ concentrations, cesium breakthrough occurred earlier because of decomposition of the active component.

Introductory experiments confirmed that cesium may be washed out of the composite absorbers. After decomposition of the active components, cesium can be eluted quantitatively from the AMP-PAN, and $95 \%$ of cesium can be eluted from the KCoFC-PAN. Regeneration of both absorbers for repetitive use was also found to be possible. The main result of the study is that PAN was proven to be a versatile polymer capable of forming porous composite absorbers with a large number of primary absorbers. The composite absorbers proved to be capable of withstanding the harsh acidic and alkaline conditions and significant radiation doses that may be expected in the treatment of US Department of Energy wastes. A field demonstration is proposed as a follow-on activity.
\end{abstract}




\section{Acknowledgments}

This research project was managed by Sandia National Laboratories under US Department of Energy Technical Task Plan (TTP) AL-234302, International Efficient Separations. This task was funded and pursued under the direction of Teresa B. Fryberger, formerly Program Manager, DOE/EM-53. The Principal Investigator was Rudolph V. Matalucci, formerly of the Sandia International Programs Department 6907.

The technical and programmatic support efforts by the Institute for Central and Eastern European Cooperative Environmental Research (ICEECER) at Florida State University (FSU), Tallahassee, Florida under Sandia Contract AE-4761, are acknowledged. More specifically, the technical liaison and subcontract support provided by John E. Moerlins and Roy C. Herndon from the ICEECER are gratefully appreciated. This work was accomplished by the Czech Technical University in Prague (CTU), Czech Republic, via an Agreement for Services (FSU/CTU-1) between FSU and CTU.

The technical guidance, suggestions, and significant contributions made by Norman E. Brown and S. Frederic Marsh of the Sandia Environmental Technology Department 6624 and Jack Watson from Oak Ridge National Laboratories are also appreciated. Their technical guidance, especially during the planning and execution of the experimental work, was valuable for the successful progress made by this project. 


\section{Preface}

The text for this report was provided in English by the authors at the Czech Technical University (CTU). Minor editing was accomplished at Sandia National Laboratories to clarify technical terminology without attempting to modify the content as established by the authors.

This report describes the second phase of a two-phase experimental effort that was accomplished at CTU under a service agreement, through Sandia National Laboratories, with Florida State University. The results obtained under the first phase of this effort were published in Sandia Report SAND95-2729, printed November 1995.

The original program definition was to study ion exchange in PAN absorber matrices at flow rates from 0.5 to $20 \mathrm{BV} / \mathrm{hr}$. During the course of the study, the flow rate was changed to 25 to $100 \mathrm{BV} / \mathrm{hr}$ by Jack Watson (ORNL) on behalf of DOE at Prague on September .8, 1995. The intent of the change was to evaluate the effect of PAN on ion-exchange kinetics at very high flow rates.

The main finding of the study is that the PAN binder is stable over a wide range of $\mathrm{pH}$ values and that it does not interfere with ion-exchange kinetics. Stability of the ion exchanger is the limiting factor under these test conditions. As a result, this study was conducted under more severe $\mathrm{pH}$ and flow rate conditions than would be encountered in DOE radioactive waste treatment studies. If $\mathrm{KCoFC/PAN} \mathrm{or} \mathrm{AMP/PAN} \mathrm{composites} \mathrm{are} \mathrm{to} \mathrm{be} \mathrm{considered} \mathrm{for} \mathrm{DOE} \mathrm{radioactive} \mathrm{waste} \mathrm{treat-}$ ment, it will be necessary to define the processing conditions under which the absorber is demonstrated to be stable. 


\section{Contents}

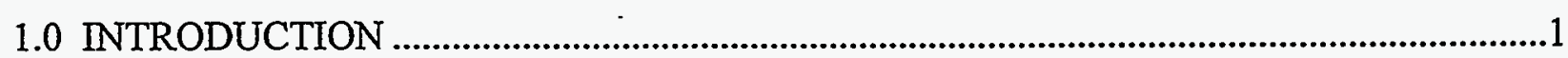

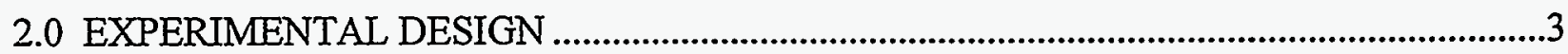

2.1 Rationale of the Experimental Program...............................................................................

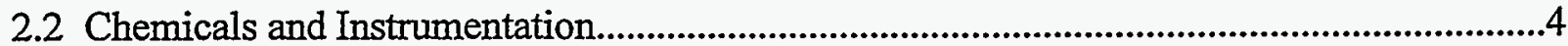

2.3 Experimental Methods .....................................................................................................

2.3.1 Swelling Measurements ..................................................................................................5

2.3.2 Determination of Sorption Capacity ...............................................................................6

2.3.3 Breakthrough Curve Measurement ..................................................................................

2.3.4 Cesium Elution / Absorbers Regeneration........................................................................7

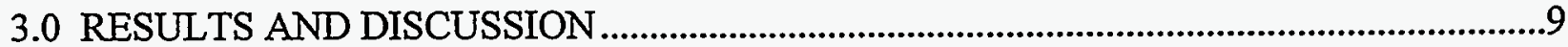

3.1 Sorption Capacity of AMP-PAN and KCoFC-PAN Absorbers ...........................................9

3.2 Separation of Cesium from Acidic Simulant Solutions ........................................................10

3.2.1 AMP-PAN Absorber.........................................................................................10

3.2.2 KCoFC-PAN Absorber ..................................................................................................11

3.2.3 Comparison of the AMP-PAN and KCoFC-PAN Composite Absorbers ....................12

3.3 Separation of Cesium from Alkaline Simulant Solutions......................................................13

3.3.1 Evaluation of the Performance of KCoFC-PAN, NiFC-PAN, and CoFC-PAN

Composite Absorbers in $1 M \mathrm{NaOH}+1 \mathrm{M} \mathrm{NaNO}_{3}$.................................................13

3.3.2 Influence of $\mathrm{NaOH}$ Concentration on the Performance of the KCoFC-PAN Absorber.......................................................................................15

3.4 Elution of Cesium and/or Regeneration of the Absorbers ......................................................17

3.4.1 AMP-PAN Absorber..............................................................................................17

3.4.2 KCoFC-PAN Absorber .........................................................................................19

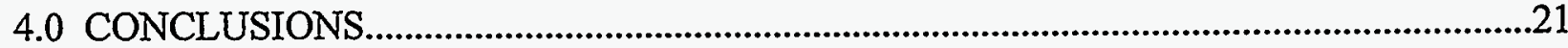

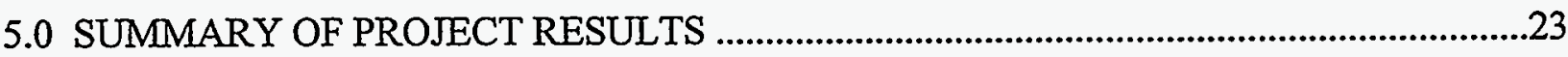

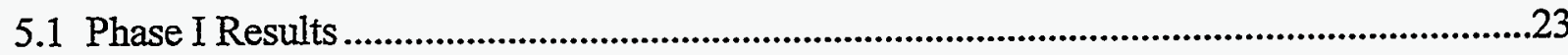

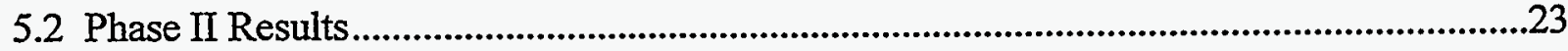

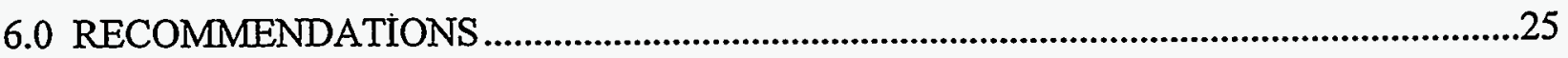

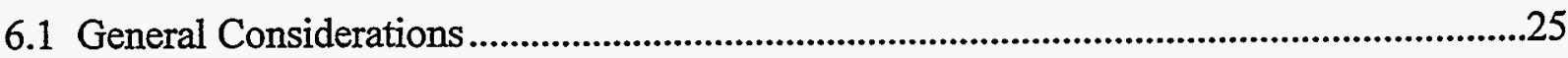

6.2 Follow-on Activities ....................................................................................................26

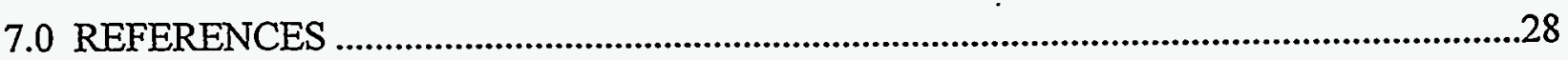




\section{List of Figures}

Figure 1. Influence of the flow rate on the breakthrough of ${ }^{137} \mathrm{Cs}$ through a column of AMP-PAN absorber. Grain size $0.3-0.7 \mathrm{~mm} ; 1 M \mathrm{HNO}_{3}+1 M \mathrm{NaNO}_{3}$; $2 \times 10^{-5} \mathrm{M} \mathrm{CsCl}$.

Figure 2. Influence of flow rate on the breakthrough of ${ }^{137} \mathrm{Cs}$ through a column of KCoFC-PAN absorber. Grain size $0.3-0.63 \mathrm{~mm} ; 1 M \mathrm{HNO}_{3}+1 M \mathrm{NaNO}_{3}$; $2 \times 10^{-5} \mathrm{M} \mathrm{CsCl}$.

Figure 3. Breakthrough of ${ }^{137} \mathrm{Cs}$ through columns with various ferrocyanide-based composite absorbers. Grain size $0.63-1.0 \mathrm{~mm} ; 1 M \mathrm{NaOH}+1 M \mathrm{NaNO}_{3}$; $2 \times 10^{-4} \mathrm{M} \mathrm{CsCl}$.

Figure 4. Influence of the flow rate on the breakthrough of ${ }^{137} \mathrm{Cs}$ through a column of KCoFC-PAN absorber. Grain size $0.63-1.0 \mathrm{~mm} ; 1 M \mathrm{NaOH}+1 M \mathrm{NaNO}_{3}$; $2 \times 10^{-4} \mathrm{MCsCl}$.

Figure 5. Influence of the flow rate on the breakthrough of ${ }^{137} \mathrm{Cs}$ through a column of KCoFC-PAN absorber. Grain size $0.3-0.63 \mathrm{~mm} ; 0.1 \mathrm{M} \mathrm{NaOH}+1 M \mathrm{NaNO}_{3}$; $2 \times 10^{-4} \mathrm{MCsCl}$.

Figure 6. Influence of $\mathrm{NaOH}$ concentration on the breakthrough of ${ }^{137} \mathrm{Cs}$ from $1 \mathrm{M} \mathrm{NaNO}_{3}$ through a column of KCoFC-PAN absorber. Grain size $0.3-0.63 \mathrm{~mm}$; $2 \times 10^{-4} \mathrm{M} \mathrm{CsCl}$.

Figure 7. Elution of ${ }^{137} \mathrm{Cs}$ from a column of AMP-PAN absorber by various elution agents. Grain size $0.3-0.7 \mathrm{~mm}$; BV $=10 \mathrm{~mL}$; flow rate $3 \mathrm{BV} / \mathrm{hr}$.

Figure 8. Comparison of the breakthrough of ${ }^{137} \mathrm{Cs}$ through columns of fresh (1) and regenerated (2) AMP-PAN absorbers. Grain size 0.3-0.7 mm; $1 M \mathrm{HNO}_{3}+$ $1 M \mathrm{NaNO}_{3} ; 2 \times 10^{-5} \mathrm{M} \mathrm{CsCl}$

Figure 9. Elution of ${ }^{137} \mathrm{Cs}$ from a column of $\mathrm{KCoFC}-\mathrm{PAN}$ absorber by various elution agents. Grain size $0.3-0.63 \mathrm{~mm} ; \mathrm{BV}=1.8 \mathrm{~mL}$; flow rate $6.6 \mathrm{BV} / \mathrm{hr}$.

\section{List of Tables}

Table 1 Characteristics of Selected Composite Absorbers .5

Table 2 Properties of the AMP-PAN and KCoFC-PAN Composite Absorbers

Table 3. Comparison of Cesium Breakthroughs from $1 M \mathrm{HNO}_{3}+1 M \mathrm{NaNO}_{3}+$ $2 \times 10^{-5} \mathrm{M}$ CsCl Solution through a Column of AMP-PAN Composite Absorber (grain size $0.3-0.7 \mathrm{~mm}$ ) at Various Flow Rates

Table 4. Influence of $\mathrm{NaOH}$ Concentration on the Breakthrough of Cesium from

$1 \mathrm{M} \mathrm{NaNO}_{3}+2 \times 10^{-4} \mathrm{M} \mathrm{CsCl}$ Solution at a Flow Rate of $\sim 54 \mathrm{BV} / \mathrm{hr}$. Grain size

$0.3-0.63 \mathrm{~mm}$; KCoFC-PAN composite absorber 


\subsection{INTRODUCTION}

This report summarizes experimental results obtained at the Department of Nuclear Chemistry of the Czech Technical University (CTU) for the second phase of a project designed to evaluate polyacrylonitrile (PAN) as a binding polymer for absorbers used to treat liquid radioactive wastes. CTU in Prague, Czech Republic, was contracted by Florida State University to perform this study under Agreement for Services No. FSU/CTU-1. The contract was comanaged by Sandia National Laboratories (SNL) under the guidance of R.V. Matalucci. The original experimental scope of the project was modified and agreed on by these participants.

The final agreement delineates a two-phase project. Phase I established and demonstrated the stability of PAN in acidic and alkaline solutions using actual performance data with or without absorbers. This phase of the effort evaluated both the chemical and radiation stability of PAN using laboratory techniques. A summary of the Phase I results was presented at the ICEM'95 conference in Berlin, ${ }^{1}$ and detailed results were presented in a report published by SNL. ${ }^{2}$

The results achieved in Phase I confirmed that PAN is a versatile polymer capable of forming porous composite absorbers with small particles of a large number of primary absorbers. The composite absorbers are capable of withstanding harsh acidic and alkaline conditions and significant radiation doses. In acidic solutions, the stability of PAN binder is not limited by either chemical or radiation decomposition (in $1 \mathrm{M} \mathrm{HNO}_{3}+1 \mathrm{M} \mathrm{NaNO}$ solution to radiation doses of $\left.10^{6} \mathrm{~Gy}\left[10^{8} \mathrm{rad}\right]\right)$. PAN binder may thus be used for the preparation of composite absorbers to treat acidic wastes from US Department of Energy (DOE) facilities. The same conclusion was found to be valid for alkaline solutions with $\mathrm{pH}$ to 13 .

In highly alkaline solutions (concentrations of $\mathrm{NaOH}>1 \mathrm{~mole} / \mathrm{L}$ ), specifically in the presence of $\mathrm{NaNO}_{3}$, the stability of the tested type of PAN polymer was sufficient for applications of composite absorbers extending to 10 days. Because of the high sorption rate achievable with these absorbers, the sorption capacity of practically any active component will usually be exhausted earlier. The stability achieved is thus sufficient for most applications in the DOE complex. The positive influence of $\gamma$-radiation on the stability of PAN (ascribed to radiation crosslinking) was also observed. Possibilities for further improving the chemical stability of the binding polymer in alkaline media (if necessary) were suggested and are currently being tested.

Phase II of this project was designed to establish and demonstrate the performance of the PAN material using a specified PAN/absorber combination and the results from Phase I for separations of either simulated or actual radioactive liquid waste. Phase II was conducted to provide the performance data that will be used to more specifically select the application of the evaluated PAN/absorber combinations. Accordingly, the following work was proposed for inclusion in Phase II: $:^{3}$

A. Selection of the absorber that provides the most utility to the specified radioactive waste problems: ammonium molybdophosphate (AMP) for cesium removal in acidic solution and titanium dioxide/HTO for strontium removal in alkaline solutions.

B. Selection of the PAN/absorber combinations (one or two) with specified percent of binder, temperatures, waste solutions that compare with DOE Hanford and Idaho waste forms, and binder particle size (possibly 20-50 mesh). 
C. Evaluation of the sorption efficiency of the PAN/absorber as a function of three different flow rates. Flow rates from 0.5 to 20 column volumes (CV) per hour were recommended for evaluation.

D. Application of existing testing techniques to establish decontamination factors for the simulated waste forms. The use of columns $1 \mathrm{~cm}$ in diameter and $10 \mathrm{~cm}$ or more in length is acceptable. Sandia technical representatives will select the testing method (i.e., cold chemical, tracer studies, or actual waste) based on the approach and rationale proposed by the Principal Investigator.

E. Comparison of the performance of the PAN binder (as a hydrophilic polymer) with the performance of currently applied hydrophobic binders in the separation process.

F. Development and identification of the appropriate future application of PAN/absorber combinations for the current waste forms in the DOE complex.

G. Preparation of a technical report and documentation of data that summarize all the work accomplished in both phases of this effort. This report will be submitted to Sandia within 30 days after completion of the total task.

A technical review and decision at the completion of the first phase were required before laboratory testing could proceed to the second phase. Final approval to begin Phase II work was issued by Sandia in August 1995 after judging the results presented in the Phase I Draft Report. ${ }^{2}$ Some aspects of the experimental program were discussed with S. Fredric Marsh of Sandia. The complete program of experiments for Phase II was then presented and approved at a meeting between representatives of the DOE (headed by G. De La Torre and J. Watson) and the Nuclear Research Institute in Prague, on 8 September 1995.

This report is the Phase II Final Report, the second and last deliverable due under Agreement for Services No. FSU/CTU-1. As required by the Agreement, this report summarizes all work accomplished. 


\subsection{EXPERIMENTAL DESIGN}

\subsection{Rationale of the Experimental Program}

Final selection of PAN/absorber combinations, target radionuclides, simulated waste compositions, and experimental conditions for the Phase II experiments was based on the following requirements:

- demonstration of the performance of PAN as a binding polymer for absorbers used to treat both acidic and alkaline liquid radioactive wastes,

- demonstration of the performance of selected PAN/absorber combinations with simulant wastes that compare with Hanford and Idaho waste forms, and

- maintenance of continuity with the work performed in Phase I of the project.

Based on these requirements, the composition of the simulant waste solutions chosen for all the basic tests was the same as in Phase I: $1 M \mathrm{HNO}_{3}+1 M \mathrm{NaNO}_{3}$ and $1 M \mathrm{NaOH}+1 M$ $\mathrm{NaNO}_{3}$ for simulants of acidic and alkaline wastes, respectively. These simulants compare reasonably well with Idaho waste forms. Because of the limited stability of PAN binder in alkaline solutions, the concentrations of sodium hydroxide and sodium nitrate were not increased, to match the Hanford waste forms more closely.

Selection of target radionuclides (radiocesium and/or radiostrontium) is closely connected to selection of the respective PAN/absorber combinations. To follow the guidelines of the Phase II program as defined in the Agreement, and to maintain continuity with the Phase I work, one of the composite absorbers was selected to be the ammonium molybdophosphate active component in PAN binding polymer, AMP-PAN. This absorber is very selective for cesium removal from acidic solutions and was considered to be a candidate for treatment of Idaho liquid waste forms.

Because the main goal of Phase II work was not to find the "best" absorber (active component) for the selected simulants but rather to demonstrate the performance of PAN binder, the same target radionuclide was selected for both the acidic and alkaline simulants. This selection was determined to be more practical and potentially yield more illustrative results. Because one of the selected composite absorbers was AMP-PAN, the target radionuclide for all the tests was ${ }^{137} \mathrm{Cs}$. The best comparison of PAN binder performance in acidic and alkaline solutions results from testing the same composite absorber (with the same active component) in both simulants.

Following the data available in the literature, the best active component for removing ${ }^{137} \mathrm{Cs}$ from both acidic and alkaline simulants should be a crystalline silicotitanate. ${ }^{4-9}$ Although some of these silicotitanates are now commercially available in the USA (e.g.; UOP's IONSIV ${ }^{\text {rM }}$ IE-910 powder), ${ }^{9}$ they are not available for sale outside the USA pending resolution of confidentiality and licensing issues. Thus a search for other candidate materials was necessary; specifically, absorbers from the group of ferrocyanides were considered.

Generally, ferrocyanides are among the most promising absorbers for treating acidic wastes. Unfortunately, most ferrocyanides decompose at $\mathrm{pH}>10$. Special procedures have been developed to improve the stability and performance of some ferrocyanides at high $\mathrm{pH}$ values. ${ }^{10} \mathrm{Sam}$ ples of potassium-cobalt ferrocyanide $(\mathrm{KCoFC})$ were recently found to yield very good results (high $K_{D}$ values) in alkaline solutions; some contained free $\mathrm{OH}$ concentrations as high as 
1.68 mole/L. ${ }^{6,8}$ This explains the selection of potassium-cobalt ferrocyanide in PAN binding polymer, KCoFC-PAN, for testing in both acidic and alkaline simulants. The KCoFC-PAN was prepared from the $\mathrm{KCoFC}$ active component following the procedure of Prout et al. ${ }^{10,11}$

The last variable was the concentration of cesium carrier. Total cesium concentrations in single waste types unfortunately are not included in the major databases. ${ }^{12}$ To ensure that the results would be realistic, the concentration of cesium carrier was selected to match that used in recent studies with comparable simulants. The concentration of cesium carrier in acidic simulant was selected to be $2 \times 10^{-5}$ mole/L, based on the data of Marsh et al. ${ }^{4-9}$ and Herbst et al. ${ }^{13}$ The concentrations of cesium carrier in alkaline simulants used in recent studies exhibit much larger spread, ${ }^{4-6}$ from $4.5 \times 10^{-8} \mathrm{~mole} / \mathrm{L}$ to $5 \times 10^{-4} \mathrm{~mole} / \mathrm{L}$. In most studies, the carrier concentrations are significantly higher in alkaline than in acidic simulants. For this reason the concentration of cesium carrier for our tests was selected to be $2 \times 10^{-4} \mathrm{~mole} / \mathrm{L}$.

To demonstrate one of the main advantages of PAN-based composite absorbers-the rapid kinetics of ion-exchange-the selection of flow rates was increased from the initial range of 0.5 20 bed volumes (BV) per hour to $\sim 25$ to $\sim 100 \mathrm{BV} / \mathrm{hr}$. The guidelines and rationale for the described experimental conditions were presented and approved at the meeting of DOE and CTU representatives in Prague on 8 September 1995.

\subsection{Chemicals and Instrumentation}

All active components used for the preparation of composite absorbers were CTU laboratory preparations:

- Dry powdered AMP was prepared following the published procedure. ${ }^{14}$

- $\mathrm{KCoFC}$ was synthesized following the procedure described by Prout et al. ${ }^{10,11}$

- Nickel ferrocyanide (NiFC) and cobalt ferrocyanide $(\mathrm{CoFC})$ were prepared by procedures developed in the CTU laboratory. ${ }^{15}$

All metal ferrocyanides were prepared in finely powdered form (grain size $<0.1 \mathrm{~mm}$ ). The respective composite absorbers were prepared from the powdered active components following the general procedure of Šebesta. ${ }^{16}$ The main characteristics of the composite absorbers used are summarized in Table 1. All chemicals used for the preparation of simulant solutions and elution agents were p.a. grade commercial preparations. Cesium carrier was added to the simulants in the form of $\mathrm{CsCl}$ solution. The ${ }^{137} \mathrm{Cs}$ tracer was a carrier-free solution of $\mathrm{CsCl}$ in $0.1 \mathrm{M} \mathrm{HCl}$ (40 MBq ${ }^{137} \mathrm{Cs}$ in $0.63 \mathrm{~mL}, \mathrm{RCs}-34$, Poland).

Sorption experiments were performed at ambient temperature in low-pressure polypropylene Econo-Pac columns (ID $\sim 1.5 \mathrm{~cm}, \mathrm{BV}$ to $20 \mathrm{~mL}$ ) or Poly-Prep columns (ID $\sim 0.8 \mathrm{~cm}, \mathrm{BV}$ to $2 \mathrm{~mL}$; all BIO-RAD, USA) equipped with 10-mL reservoirs and end caps. Polyethylene bed support discs of $35-\mu \mathrm{m}$ porosity were fixed at the column bottoms. In the Econo-Pac columns, similar discs were used as filters at the top of the absorber bed. The flow rate was controlled by means of a peristaltic mini-flow pump PCD 22 (Kouřil, Kyjov, Czech Republic). Individual fractions of the effluent were collected either by means of an SF-62 fraction collector (Mikrotechna, Prague, Czech Republic) or manually. 
Table 1 Characteristics of Selected Composite Absorbers

\begin{tabular}{|c|l|c|c|c|}
\hline $\begin{array}{c}\text { Absorber } \\
\text { Code }\end{array}$ & \multicolumn{1}{c|}{$\begin{array}{c}\text { Active } \\
\text { Component }\end{array}$} & $\begin{array}{c}\text { Active Component in } \\
\text { Dry Residue (\%) }\end{array}$ & Batch & $\begin{array}{c}\text { Grain Size } \\
\text { (mm) }\end{array}$ \\
\hline AMP-PAN & $\begin{array}{l}\text { Ammonium } \\
\text { molybdophosphate } \\
\text { Potassium-cobalt } \\
\text { ferrocyanide }\end{array}$ & 85.7 & FL-2/95 & $0.3-0.7$ \\
KCoFC-PAN & 85.7 & R-6/95 & $0.3-0.63$ \\
\hdashline KCoFC-PAN & $\begin{array}{l}\text { Potassium-cobalt } \\
\text { ferrocyanide } \\
\text { Nickel }\end{array}$ & 85.7 & R-6/95 & $0.63-1.0$ \\
NiFC-PAN & $\begin{array}{l}\text { ferrocyanide } \\
\text { Cobalt } \\
\text { ferrocyanide }\end{array}$ & 85.7 & LANL-3/95 & $0.63-1.0$ \\
CoFC-PAN & 81.8 & LANL-3/95 & $0.63-1.0$ \\
\hline
\end{tabular}

The $\gamma$-activity of the liquid samples, originating from sorption capacity determinations and elution/regeneration experiments, was measured using an NV 3102 single-channel analyzer connected to a scintillation counter with a well-type $\mathrm{NaI}(\mathrm{Tl})$ detector (all Tesla, Czech Republic). The concentration of ${ }^{137} \mathrm{Cs}$ in the column effluents was determined by measuring its ${ }^{137 \mathrm{~m}} \mathrm{Ba}$ daughter activity using gamma spectrometry. Aliquots of effluents were transferred into $450-\mathrm{mL}$ Marinelli beakers (U'VVVR, Prague, Czech Republic). The samples were counted on a PIGC-22 HPGe coaxial detector (Princeton Gamma Technologies, USA) coupled via an Ortec 672 Spectroscopy Amplifier to an Ortec 919 Spectrum Master Multichannel Buffer (all EG\&G Ortec, USA) and controlled by an IBM-compatible personal computer. The SPDEMOS software package was used for spectra evaluation. ${ }^{17}$

For dewatering the composite absorbers by filtration, an Amicon (USA) Sterifil filtration unit equipped with glass microfiber filters (Whatman GF/C, USA) was used. In addition, standard laboratory equipment (desk-top centrifuge, ovens and/or drying ovens, sieves, balances, pipettes, etc.) was used.

\subsection{Experimental Methods}

\subsubsection{Swelling Measurements}

Swelling determinations were performed in distilled water for KCoFC-PAN or in $10^{-3} \mathrm{M}$ $\mathrm{HNO}_{3}$ for AMP-PAN (to avoid decomposition of the molybdophosphate complex ion). The beads of the absorbers were dewatered by centrifugation for $15 \mathrm{~min}$. at $3000 \mathrm{rpm}$ $(\mathrm{G}=6409 \mathrm{~m} / \mathrm{sec}$ ) in a special glass tube equipped with a glass frit. The excess water was collected in absorbent cotton at the bottom of the tube. About $1.5 \mathrm{~g}$ of dewatered beads was then dried for $4 \mathrm{hr}$ at $70^{\circ} \mathrm{C}$. Optimum revolution speed, time of centrifugation, temperature, and drying time were determined in preliminary trial experiments. Swelling ( $S$, percent water) was calculated from the measured loss of weight following the formula: 


$$
S=\frac{m_{s}-m_{d}}{m_{s}} \times 100
$$

. where $m_{s}$ is the weight of the aliquot of the swollen absorbers beads and $m_{d}$ is its weight after drying to constant weight.

"Apparent swelling" was also determined for the absorbers used in the column sorption experiments. Approximately $200 \mathrm{~mL}$ of swollen absorbers were dewatered by filtering off the "free" interstitial water. Aliquots of the filtered and homogenized absorbers were dried as described previously. "Apparent swelling" was then calculated using the formula given in Equation 1.

\subsubsection{Determination of Sorption Capacity}

The sorption capacity of the absorbers was determined by passing $25 \mathrm{~mL}$ of the feed solution in the downward direction through a Poly-Prep column with $\sim 1 \mathrm{~g}$ of the exactly weighed swollen composite absorber. The absorbers were preconditioned by washing with $10 \mathrm{~mL}$ of $1 M$ $\mathrm{HNO}_{3}+1 M \mathrm{NaNO}_{3}$ at a flow rate of $1 \mathrm{~mL} / \mathrm{min}$. The column was closed by an air-tight lid to keep the solution level above the absorber constant. A flow rate of $0.3 \mathrm{~mL} / \mathrm{min}$. $(10 \mathrm{BV} / \mathrm{hr})$ was maintained by a peristaltic pump. The effluent and all the washes were collected and their volume was adjusted to $50 \mathrm{~mL}$. Sorption capacity $(q)$ of the absorber (per gram of the swollen absorber) was calculated using measured activities of aliquots of feed and effluent following the equation:

$$
q=\frac{N_{1}-N_{2}}{m}=\frac{c V_{f}\left(1-\frac{A_{e} V_{e}}{A_{f} V_{f}}\right)}{m} \quad \text { (mmole.g) }
$$

where $m$ is the weight of the tested sample of the absorber $(g) ; N_{1}$ and $N_{2}$ are the number of mmoles of $\mathrm{CsCl}$ in the feed and effluent, respectively; $c$ is the molar concentration of $\mathrm{CsCl}$ in the feed (mole/L), $A_{f}$ and $A_{e}$ are activities of 1-mL aliquots of the feed and the effluent, respectively; and $V_{f}$ and $V_{e}$ are volumes of the feed and effluent (mL), respectively.

Swelling-corrected values of sorption capacities $\left(q^{\prime}\right)$ were calculated from Equation 2 for $q$ calculation by expressing this quantity per gram of dry composite absorber instead of per gram of swollen absorber. The weight of the dry absorber $\left(m_{d}\right)$ was calculated from the weight of the swollen absorber and its swelling following Equation 3:

$$
m_{d}=\left(1-\frac{S}{100}\right) \times m_{s}
$$

where $m_{s}$ is the weight of the swollen absorber and $S(\%)$ is its swelling, determined as described above. 


\subsubsection{Breakthrough Curve Measurement}

The study of cesium uptake from the simulant solutions was performed at ambient temperature in the Econo-Pac columns. The bed volume of the swollen composite absorbers was $10 \mathrm{~mL}$. Feed flow was in the upward direction. The columns were closed by an air-tight end-cap equipped with polyethylene tubing for draining the effluent simulants from the columns. The end of this tubing was placed just above the upper filter disc at the top of the absorber bed. The flow rate of the feed solution was maintained by a peristaltic pump located between the feed solution reservoir and the column; the pump was connected to the column and the reservoir by polyethylene tubing.

In the experiments with acidic simulants, the absorber bed was prepared directly in the simulant used (unlabeled), the $1 M \mathrm{HNO}_{3}+1 M \mathrm{NaNO}_{3}$ solution. In the experiments with alkaline simulants, the absorber bed was prepared in distilled water (to avoid potential uncontrolled decomposition of the ferrocyanide active components before experiment startup).

All the fractions of effluents were weighed and their volumes calculated using the specific weights of the respective solutions. From these values, total volumes of the treated solutions (in $\mathrm{mL}$ ) were calculated. These values were then expressed in units of bed volumes of absorbers.

The percentage breakthrough of cesium in single fractions of the effluents was then calculated according to Equation 4:

$$
\text { Breakthrough }=\frac{A_{x}}{A_{0}} \times 100
$$

where $A_{x}$ and $A_{0}$ are count rates of aliquots of fraction $x$ and feed solution, respectively.

\subsubsection{Cesium Elution / Absorbers Regeneration}

Possible methods for eluting cesium from the absorber and/or regenerating absorber were tested for the KCoFC-PAN and AMP-PAN composite absorbers. In the tests with KCoFC-PAN, columns loaded by cesium during sorption-capacity determinations $(\mathrm{BV} \sim 1.8 \mathrm{~mL})$ were used. In the experiments with AMP-PAN absorber, columns loaded by cesium during breakthrough curve measurement from $1 M \mathrm{HNO}_{3}+1 M \mathrm{NaNO}_{3}$ simulant solution $(\mathrm{BV}=10 \mathrm{~mL})$ were used.

Because elution/regeneration tests were usually performed several days after loading the columns with cesium, the columns had to be pretreated before the elution/regeneration step. Usually, some air bubbles had formed in the absorber bed, probably by degassing of the airsaturated solution. These bubbles were removed by flushing the columns (with the aid of a syringe) at an elevated flow rate by $0.1 M \mathrm{HNO}_{3}$ or by $1 M \mathrm{HNO}_{3}+1 M \mathrm{NaNO}_{3}$ (for the AMP-PAN or KCoFC-PAN, respectively). The excess solution was drained to the top of the absorber bed, the outlet of the column was closed, and $\sim 2 \mathrm{~mL}$ of elution agent solution was pumped into the absorber bed. The columns were closed by air-tight end-caps equipped with polyethylene tubing connecting the columns to a peristaltic mini-flow pump and the elution/ regeneration agent solution reservoir. Downward liquid flow was used throughout the experiments. 
Individual fractions of eluates were collected after specified time intervals. All fractions of eluates were weighed, and their volumes were calculated using the density of the respective solutions. The content of ${ }^{137} \mathrm{Cs}$ in the eluate was determined from the measured $\gamma$-activity of aliquots of the fractions.

The AMP-PAN composite absorber regenerated by $5 \mathrm{M} \mathrm{NH}_{4} \mathrm{Cl}+0.1 \mathrm{M} \mathrm{HCl}$ was flushed with $\sim 25 \mathrm{~mL}$ of $1 M \mathrm{HNO}_{3}+1 M \mathrm{MNNO}_{3}$ at the end of regeneration. The breakthrough curve with the regenerated absorber was measured by the standard method (see Section 2.3.3).

The KCoFC-PAN composite absorber was regenerated in two successive steps. In the first step, cesium was eluted from the absorber by $100 \mathrm{~mL}$ of $4 \mathrm{M} \mathrm{HNO}_{3}+2 \times 10^{-3} \mathrm{M} \mathrm{NaNO}_{2}$ solution at a flow rate of $6.6 \mathrm{BV} / \mathrm{hr}$. In the second step, the absorber bed was reconditioned with $\sim 50 \mathrm{~mL}$ of $0.1 M \mathrm{HNO}_{3}+0.1 \mathrm{M} \mathrm{KNO}_{3}$ solution saturated by hydrazinium sulfate at a flow rate of $\sim 10 \mathrm{BV} / \mathrm{hr}$. The absorber bed was kept in this washing solution for an additional 2 weeks. The reduced absorber was then briefly flushed with $2-3 \mathrm{BV}$ of $1 M \mathrm{HNO}_{3}+1 M \mathrm{NaNO}_{3}$ solution. The sorption capacity of the regenerated KCoFC-PAN composite absorber was determined by the standard method (see Section 2.3.2). 


\subsection{RESULTS AND DISCUSSION}

\subsection{Sorption Capacity of AMP-PAN and KCoFC-PAN Absorbers}

To evaluate the separation efficiency of ${ }^{137} \mathrm{Cs}$ from the simulant solutions, the sorption capacity of the absorber bed in the column must be known. The sorption capacity of both the absorbers for cesium was determined from only the acidic simulant solution because AMP-PAN cannot be used in alkaline media; the stability of KCoFC-PAN in the alkaline simulant solution used in these experiments is also limited.

The AMP-PAN absorber was selected from the same batch used in the Phase I experiments; it differed only by the finer grain size used (see Table 1), which was necessitated by the dimensions of the experimental columns. The practical sorption capacity for cesium per gram of swol-

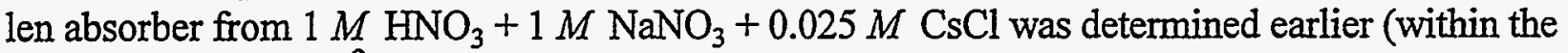
Phase I experiments). ${ }^{2}$ The practical sorption capacity of KCoFC-PAN composite absorber was determined in the same manner. Knowing the exact composition of the absorbers and their swelling percentages also enabled calculation of the practical sorption capacity of the pure active components. These characteristics are summarized in Table 2.

Table 2 Properties of the AMP-PAN and KCoFC-PAN Composite Absorbers

\begin{tabular}{|c|c|c|c|c|c|}
\hline \multirow{2}{*}{$\begin{array}{c}\text { Absorber } \\
\text { Code }\end{array}$} & \multirow{2}{*}{$\begin{array}{c}\text { Grain } \\
\text { Size } \\
\text { (mm) }\end{array}$} & \multirow{2}{*}{$\begin{array}{c}\text { Swelling } \\
\mathbf{( \% )}\end{array}$} & \multicolumn{3}{|c|}{ Sorption Capacity of the } \\
\cline { 4 - 6 } & & \multicolumn{2}{|c|}{$\begin{array}{c}\text { Absorber } \\
\text { Component }\end{array}$} \\
\hline AMP-PAN & $0.3-0.7$ & 59.0 & 0.16 & 0.39 & 0.45 \\
\hline KCOFC-PAN & $0.3-0.63$ & 60.3 & 0.28 & 0.70 & 0.82 \\
\hline
\end{tabular}

$q$ and $q^{\prime}=$ practical sorption capacity of the swollen or dry absorber, respectively.

For the dynamic column experiments, $10-\mathrm{mL}$ beds of absorbers were prepared from the absorbers dewatered by filtration. In every case, $9.25 \mathrm{~g}$ or $7.00 \mathrm{~g}$ of the AMP-PAN or KCoFC-PAN composite absorbers, respectively, was weighed exactly to prepare columns with absorber-bed volumes of $\sim 10 \mathrm{~mL}$. The "apparent swelling" (see Section 2.3.1) of absorbers dewatered in this way was found to be $69.9 \%$ and $74.2 \%$ for the AMP-PAN and KCoFC-PAN composite absorbers, respectively. The sorption capacities of the absorber beds in such columns (calculated using the "apparent swelling" values and practical sorption capacities of the dry absorbers found in 1 $M \mathrm{HNO}_{3}+1 M \mathrm{NaNO}_{3}+0.025 \mathrm{M} \mathrm{CsCl}$ ) were calculated to be 1.08 mmoles and 1.26 mmoles for the columns of AMP-PAN and KCoFC-PAN, respectively. These values are rather close; the value for the KCoFC-PAN column is higher by only $16.6 \%$. 


\subsection{Separation of Cesium from Acidic Simulant Solutions}

\subsubsection{AMP.PAN Absorber}

Breakthrough curves of ${ }^{137} \mathrm{Cs}$ from acidic simulant solutions are shown in Figure 1. This figure illustrates an unexpected finding: the efficiency of ${ }^{137} \mathrm{Cs}$ uptake increases with increasing flow rates of the feed solution.

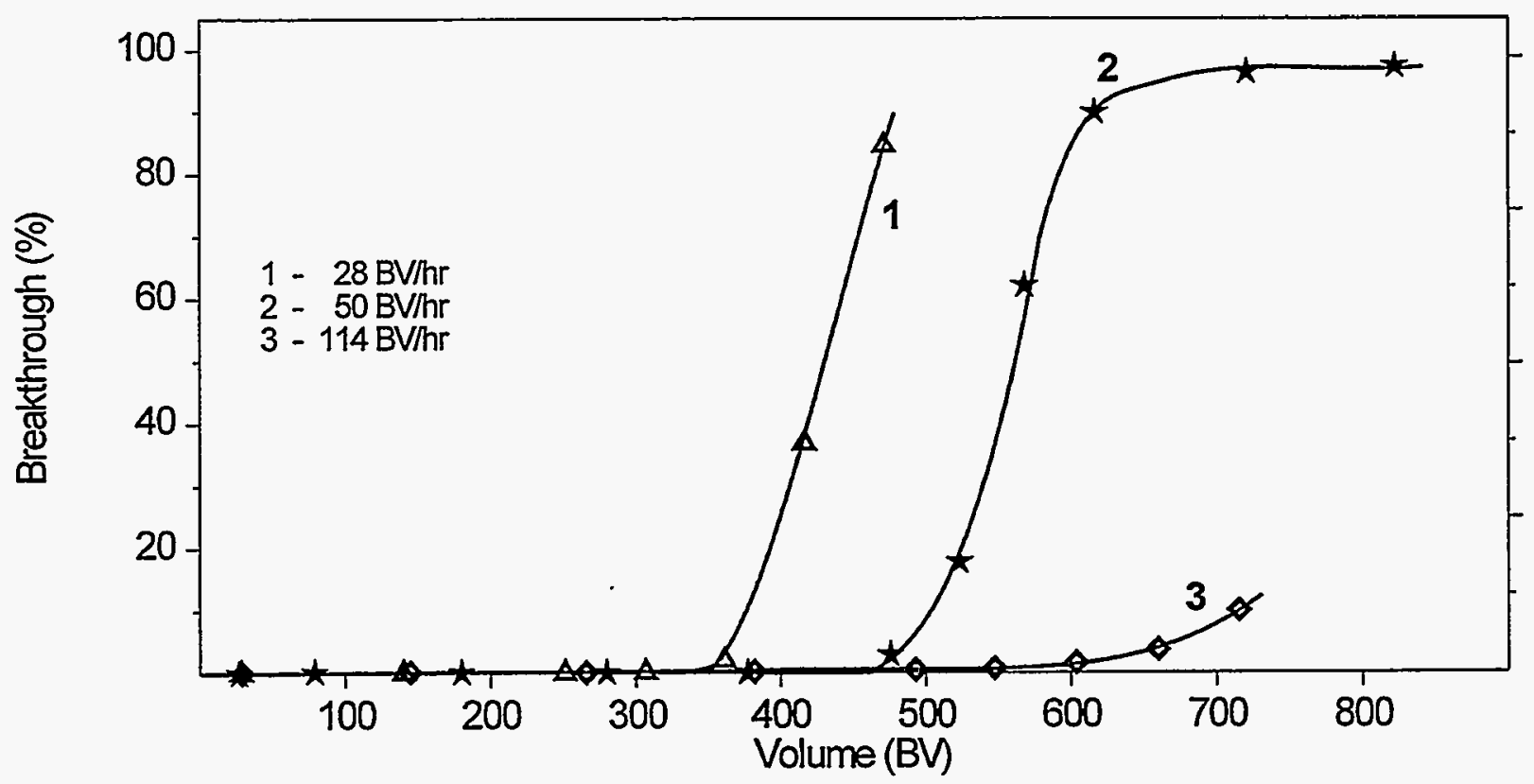

Figure 1. Influence of the flow rate on the breakthrough of ${ }^{137} \mathrm{Cs}$ through a column of AMP-PAN absorber. Grain size $0.3-0.7 \mathrm{~mm} ; 1 \mathrm{MHNO}_{3}+1 \mathrm{MNaNO}_{3} ; 2 \times 10^{-5}$ $M \mathrm{CsCl}$.

A quantitative comparison of these breakthrough curves is presented in Table 3 , which summarizes the volumes of feed solution at which the breakthrough of ${ }^{137} \mathrm{Cs}$ reached: $0.1 \%, 1 \%$, and $10 \%$ of the original concentrations for all flow rates used.

The shape of the breakthrough curves shown in Figure 1 and the data given in Table 3 can be explained by the behavior of two counteracting factors:

- the kinetics of the cesium uptake by the composite absorber; and

- partial dissolution of the ammonium molybdophosphate active component and cesium release, followed by its washing from the absorber bed. 
Table 3. Comparison of Cesium Breakthroughs from $1 M \mathrm{HNO}_{3}+1 M \mathrm{NaNO}_{3}+2 \times 10^{-5} M$ $\mathrm{CsCl}$ Solution through a Column of AMP-PAN Composite Absorber (grain size $0.3^{\circ}-0.7 \mathrm{~mm}$ ) at Various Flow Rates

\begin{tabular}{|c|c|c|c|}
\hline \multirow{2}{*}{$\begin{array}{c}\text { Breakthrough } \\
\text { (\%) }\end{array}$} & \multicolumn{3}{|c|}{ Volume of Feed Solution (BV) at each Flow Rate } \\
\cline { 2 - 4 } & $\mathbf{2 8 ~ B V / h r}$ & $\mathbf{5 0} \mathbf{~ B V / h r}$ & $\mathbf{1 1 4} \mathbf{~ B V / h r}$ \\
\hline 0.1 & 260 & 380 & 280 \\
1 & 340 & 450 & 580 \\
10 & 380 & 500 & 720 \\
\hline
\end{tabular}

Increasing the feed solution flow rate decreases the amount of ammonium molybdophosphate dissolved in the same volume of the treated solution (because of shorter contact time between the active component and the solution), thus increasing the actual practical sorption capacity of the absorber bed. This explains cesium breakthrough at larger volumes of the treated solution when higher flow rates are used.

The only exception to this rule is found in the $0.1 \%$ breakthrough, where the breakthrough volume at a flow rate of $114 \mathrm{BV} / \mathrm{hr}$ is lower than that found at $50 \mathrm{BV} / \mathrm{hr}$ and comparable to that found at $28 \mathrm{BV} / \mathrm{hr}$ (see Table 3). This effect may be unequivocally ascribed to the sorption kinetics of cesium by the AMP-PAN composite absorber. Although the kinetics are very rapid, they are not sufficient to establish sorption equilibrium (to a level sufficient for achieving decontamination factors $D_{f}>1000$ ) between the liquid and solid phases at feed solution flow rates higher than $50 \mathrm{BV} / \mathrm{hr}$.

\subsubsection{KCoFC-PAN Absorber}

The uptake of cesium by the KCoFC-PAN composite absorber was followed for two flow rates: $54 \mathrm{BV} / \mathrm{hr}$ and $102 \mathrm{BV} / \mathrm{hr}$. The measured breakthrough curves of cesium are shown in Figure 2. At a flow rate of $102 \mathrm{BV} / \mathrm{hr}$, the breakthrough of cesium was lower than $0.1 \%$ until it reached $900 \mathrm{BV}$ of treated solution. The $1 \%$ breakthrough of cesium was reached after $1400 \mathrm{BV}$ of solution. At a flow rate of $54 \mathrm{BV} / \mathrm{hr}$, the $0.1 \%$ breakthrough of cesium was reached only after $1800 \mathrm{BV}$ of solution.

These results demonstrate that the uptake of cesium improves with decreasing flow rates of the simulant solution. Nevertheless, the breakthrough curves for an even lower flow rate $(\sim 25 \mathrm{BV} / \mathrm{hr})$ were not measured for the following reasons:

- based on previous experience with ferrocyanide-type composite absorbers, no significant improvements in cesium uptake efficiency could be expected from another decrease in the flow rate, and

- within the scope of the relatively large number of experiments planned for this study, such an experiment at such a low flow rate $(\sim 25 \mathrm{BV})$ would be excessive, requiring at least 80 continuous hours. 


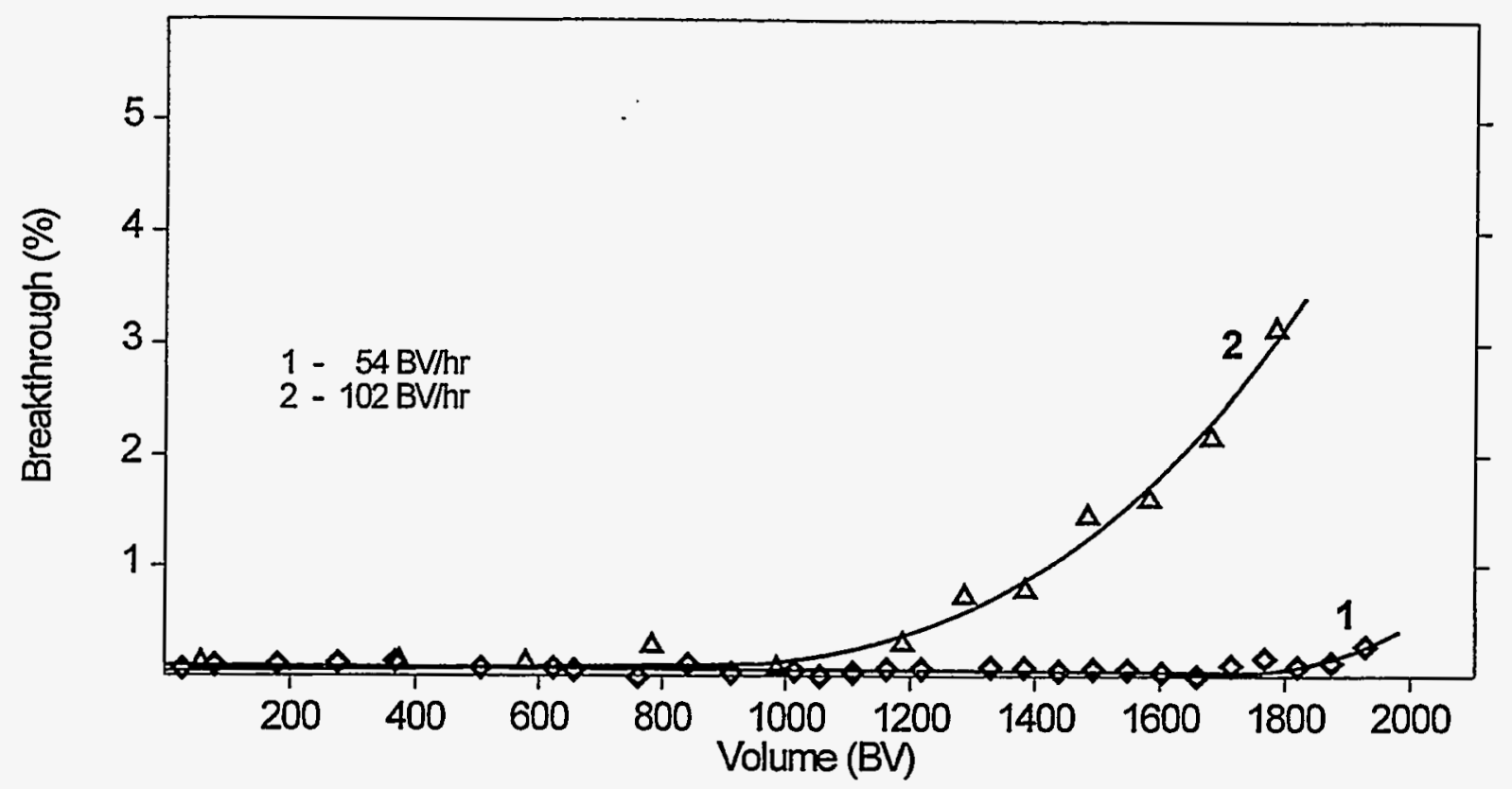

Figure 2. Influence of flow rate on the breakthrough of ${ }^{137} \mathrm{Cs}$ through a column of $\mathrm{KCoFC}$ PAN absorber. Grain size $0.3-0.63 \mathrm{~mm} ; 1 \mathrm{MHNO}_{3}+1 \mathrm{MNaNO}_{3} ; 2 \times 10^{-5} \mathrm{M}$ $\mathrm{CsCl}$.

\subsubsection{Comparison of the AMP-PAN and KCoFC-PAN Composite Absorbers}

The results of these experiments corroborated the finding that KCoFC-PAN absorber exhibits more superior properties for treating $1 M \mathrm{HNO}_{3}+1 M \mathrm{NaNO}_{3}$ acidic simulant solution than AMP-PAN. The most significant difference is the length of the sorption cycle. For example, at a flow rate of $50 \mathrm{BV} / \mathrm{hr}$, cesium breakthrough at the $0.1 \%$ level occurs after $1800 \mathrm{BV}$ of the feed solution are treated by the KCoFC-PAN composite absorber. The same breakthrough is reached as early as $380 \mathrm{BV}$ with the AMP-PAN absorber. Thus the sorption cycle of the KCoFC-PAN absorber is nearly five times longer than that of the AMP-PAN.

This difference is much larger than the difference in practical sorption capacities of the two absorbers (1.17 times higher for the KCoFC-PAN; see Section 3.1). The most probable explanation for this phenomenon is the dissolution of the ammonium molybdophosphate active component of the AMP-PAN absorber (see Section 3.2.1). Another reason may be the potentially different shapes of the sorption isotherms because the practical sorption capacities given in Table 2 were measured for different cesium concentrations than those used in the dynamic experiments $\left(0.025 \mathrm{~mole} / \mathrm{L}\right.$ versus $\left.2 \times 10^{-5} \mathrm{~mole} / \mathrm{L}\right)$. Nevertheless, the difference was not expected to result in such a large effect. 


\subsection{Separation of Cesium from Alkaline Simulant Solutions}

\subsubsection{Evaluation of the Performance of KCoFC-PAN, NiFC.PAN, and CoFC-PAN Composite Absorbers in $1 M \mathrm{NaOH}+1 \mathrm{M} \mathrm{NaNO}_{3}$}

From a review of data on the chemical stability of metal ferrocyanides published by Haas, ${ }^{18}$ it appears that potassium-cobalt ferrocyanide prepared following the procedure of Prout et al. ${ }^{10,11}$ is preferred for separating cesium from caustic solutions. Haas also states that the chemical stability of finer powders in alkaline media is worse than the stability of granular forms.

The chemical stability of composite absorbers containing finely powdered metal ferrocyanides as active components has not been studied before. Although the KCoFC-PAN composite absorber prepared from the potassium-cobalt ferrocyanide active component (synthesized following Prout et al..$^{10,11}$ ) was selected in advance for testing, some initial trial testing of other composite absorbers based on other metal ferrocyanides was also performed. Samples of composite absorbers containing cobalt ferrocyanide (CoFC-PAN) or nickel ferrocyanide (NiFC-PAN) active components were used for testing with the KCoFC-PAN absorber. Composite absorbers with larger grain sizes $(0.63-1.0 \mathrm{~mm})$ than the other experiments were used for these tests. A $10 \mathrm{~mL}$ sample of the absorbers was measured for each experiment using a graduated cylinder (instead of weighing filtered absorbers). The breakthrough curves measured in these experiments are shown in Figure 3.

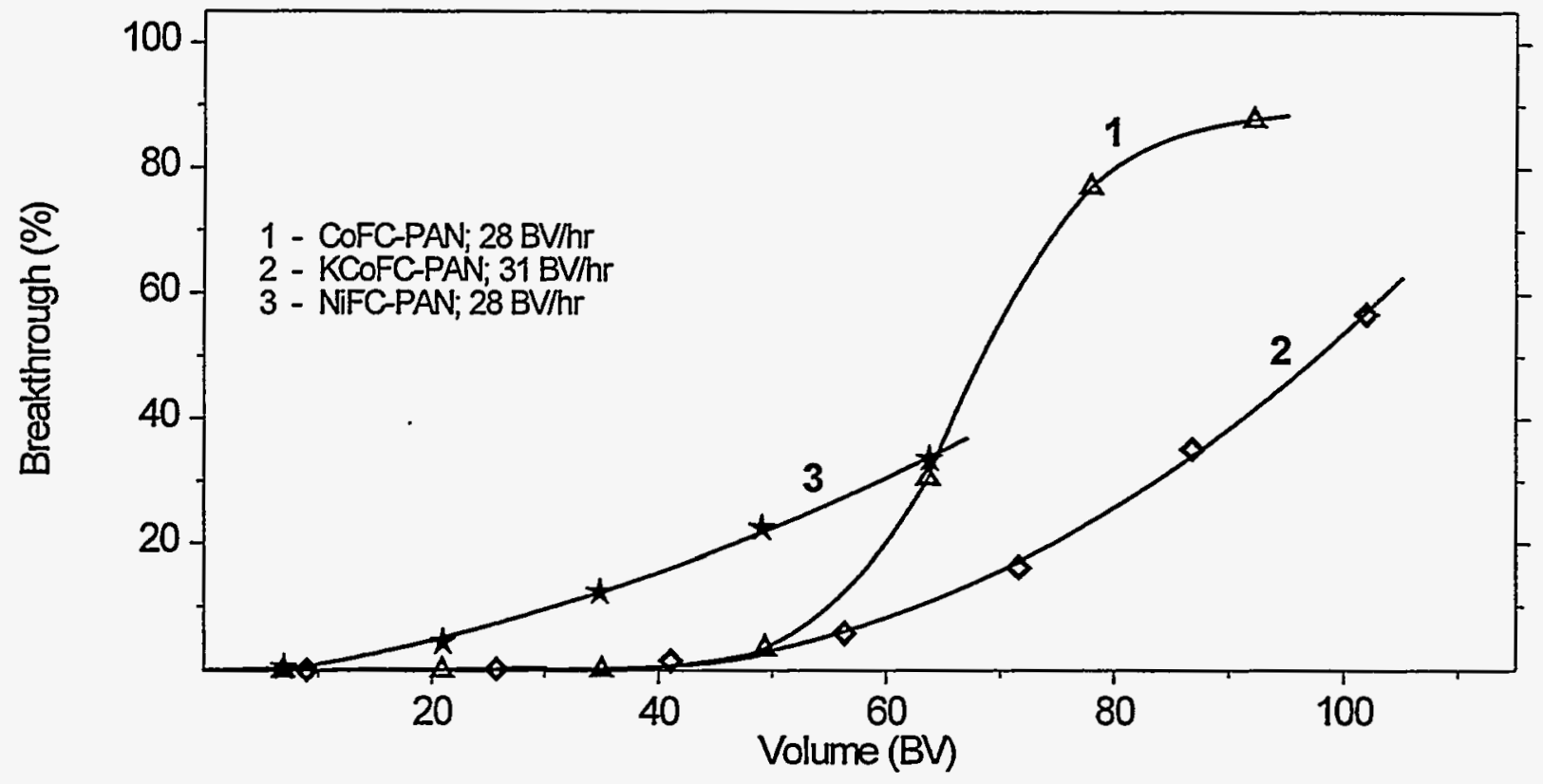

Figure 3. Breakthrough of ${ }^{137} \mathrm{Cs}$ through columns with various ferrocyanide-based composite absorbers. Grain size $0.63-1.0 \mathrm{~mm} ; 1 M \mathrm{NaOH}+1 M \mathrm{NaNO}_{3}$; $2 \times 10^{-4} M \mathrm{CsCl}$. 
Compared with the experiments performed with acidic simulant solutions, these experiments used cesium carrier concentrations that were higher by one order of magnitude, which explains the initial test flow rate of only $\sim 25 \mathrm{BV} / \mathrm{hr}$. The experiments confirmed that the best results were obtained with the KCoFC-PAN composite absorber; the least effective was the NiFC-PAN absorber. Color changes in the effluents indicated that some dissolution and decomposition of the active components occurred in all the experiments. Another conclusion that can be made from the breakthrough curves in Figure 3 is that the efficiency of cesium uptake (length of the sorption cycle until cesium breakthrough) is much lower than the results obtained in the acidic simulant solution. This is a valid conclusion even when the order-of-magnitude higher concentration of cesium in alkaline simulant solution is accounted for.

Based on these results, an experiment was designed to verify whether increasing the flow rate of the simulant solution would enhance the efficiency of cesium uptake (prolonging the sorption cycle) by shortening contact time and decreasing dissolution between the absorber and the alkaline media (similar to the effect observed for the AMP-PAN in acidic simulant solution, as noted in Section 3.2.1). The results presented in Figure 4 show that no positive effect of enhanced flow rate on cesium uptake could be observed. The reasons for this finding are obvious:

- the kinetics of cesium uptake by the KCoFC-PAN composite absorber are not rapid enough to enable "complete" uptake of cesium by the absorber bed at increased flow rates, even at the beginning of the experiment; and

- the decomposition rate of the finely powdered potassium-cobalt ferrocyanide in $1 \mathrm{MNaOH}+$ $1 \mathrm{M} \mathrm{NaNO}_{3}$ alkaline simulant solution is very rapid.

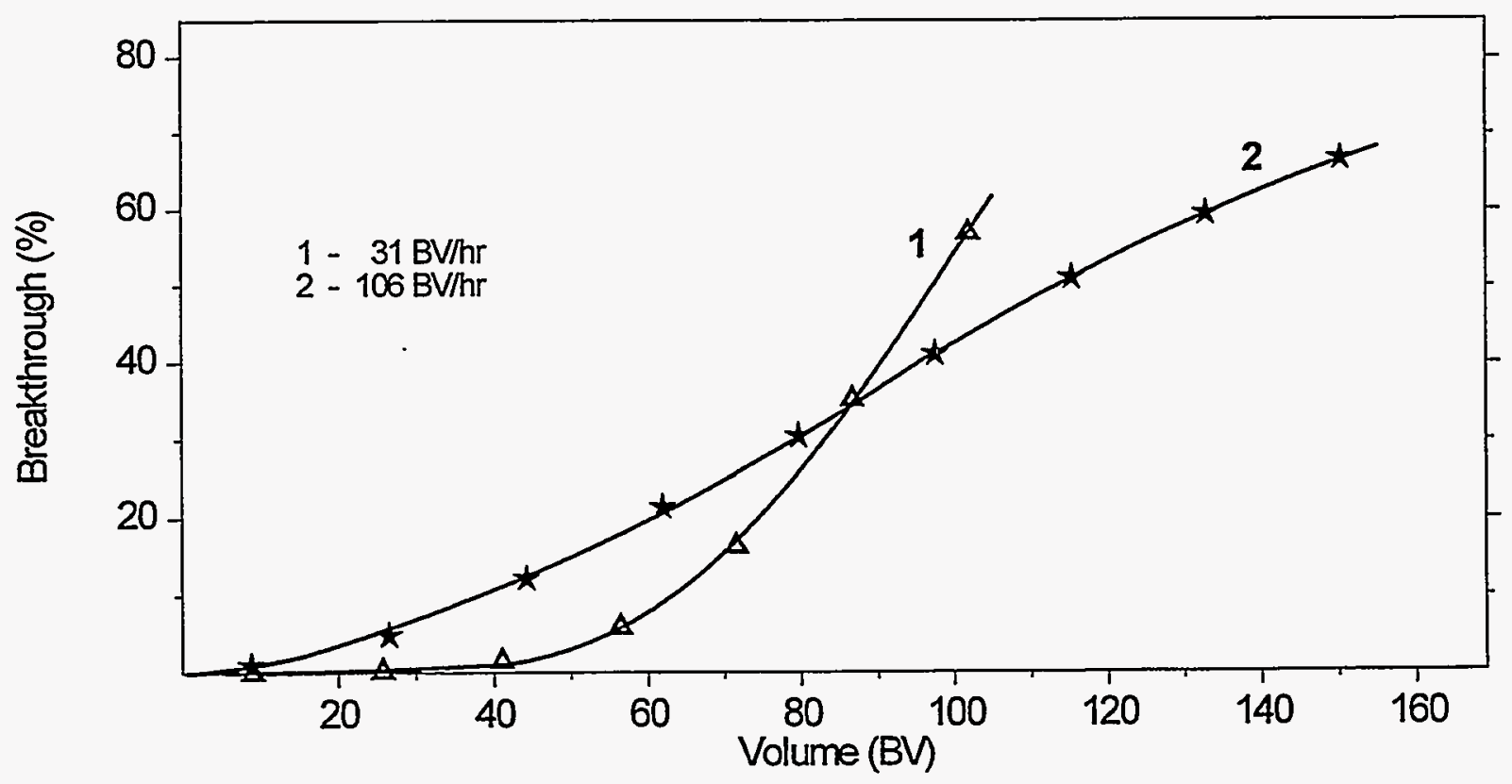

Figure 4. Influence of the flow rate on the breakthrough of ${ }^{137} \mathrm{Cs}$ through a column of KCoFC-PAN absorber. Grain size $0.63-1.0 \mathrm{~mm} ; 1 M \mathrm{NaOH}+1 M \mathrm{NaNO}_{3}$; $2 \times 10^{-4} \mathrm{M} \mathrm{CsCl}$. 


\subsubsection{Influence of $\mathrm{NaOH}$ Concentration on the Performance of the KCoFC-PAN Absorber}

On the basis of the trial experiments, the influence of $\mathrm{NaOH}$ concentration on the uptake of cesium was studied for only KCoFC-PAN composite absorber. Fine-grained absorber, weighed similarly to the experiment with acidic simulant solution, was used in these experiments.

In the first experiments, the influence of the flow rate on the efficiency of cesium sorption from $0.1 M \mathrm{NaOH}+1 M \mathrm{NaNO}_{3}$ was determined. The measured breakthrough curves are shown in Figure 5. These results show that an optimum flow rate is $\sim 50 \mathrm{BV} / \mathrm{hr}$ (see curve 2). At the lower flow rate of $28 \mathrm{BV} / \mathrm{hr}$ (curve 1), the extended time of contact between the absorber and the solutions results in greater decomposition of the active component and a decrease in the sorption capacity of the absorber bed. The breakthrough curve measured at a flow rate of $102 \mathrm{BV} / \mathrm{hr}$ is negatively influenced by the soprtion kinetics of the cesium uptake by the KCoFCPAN absorber. The contact time of the solution and absorber is too short to even approach sorption equilibrium, which results in very early breakthrough of cesium through the absorber bed. This finding agrees with the results obtained for $1 M \mathrm{NaOH}+1 M \mathrm{NaNO}_{3}$ simulant solution (see Section 3.3.1).

Therefore in further experiments the influence of $\mathrm{NaOH}$ concentration was studied at the optimum flow rate of $\sim 50 \mathrm{BV} / \mathrm{hr}$. The breakthrough curves measured for three different $\mathrm{NaOH}$ concentrations ranging from $1 M \mathrm{NaOH}$ to $0.01 \mathrm{M} \mathrm{NaOH}$ are shown in Figure 6. In Table 4 the volumes of alkaline simulant solutions that can be treated until the breakthrough of cesium equals $0.1 \%$ or $1 \%$ are given for more detailed comparison. The results in Table 4 demonstrate that decreasing the $\mathrm{NaOH}$ concentration by an order of magnitude doubles the volume of solution that can be treated before an equivalent breakthrough of cesium.

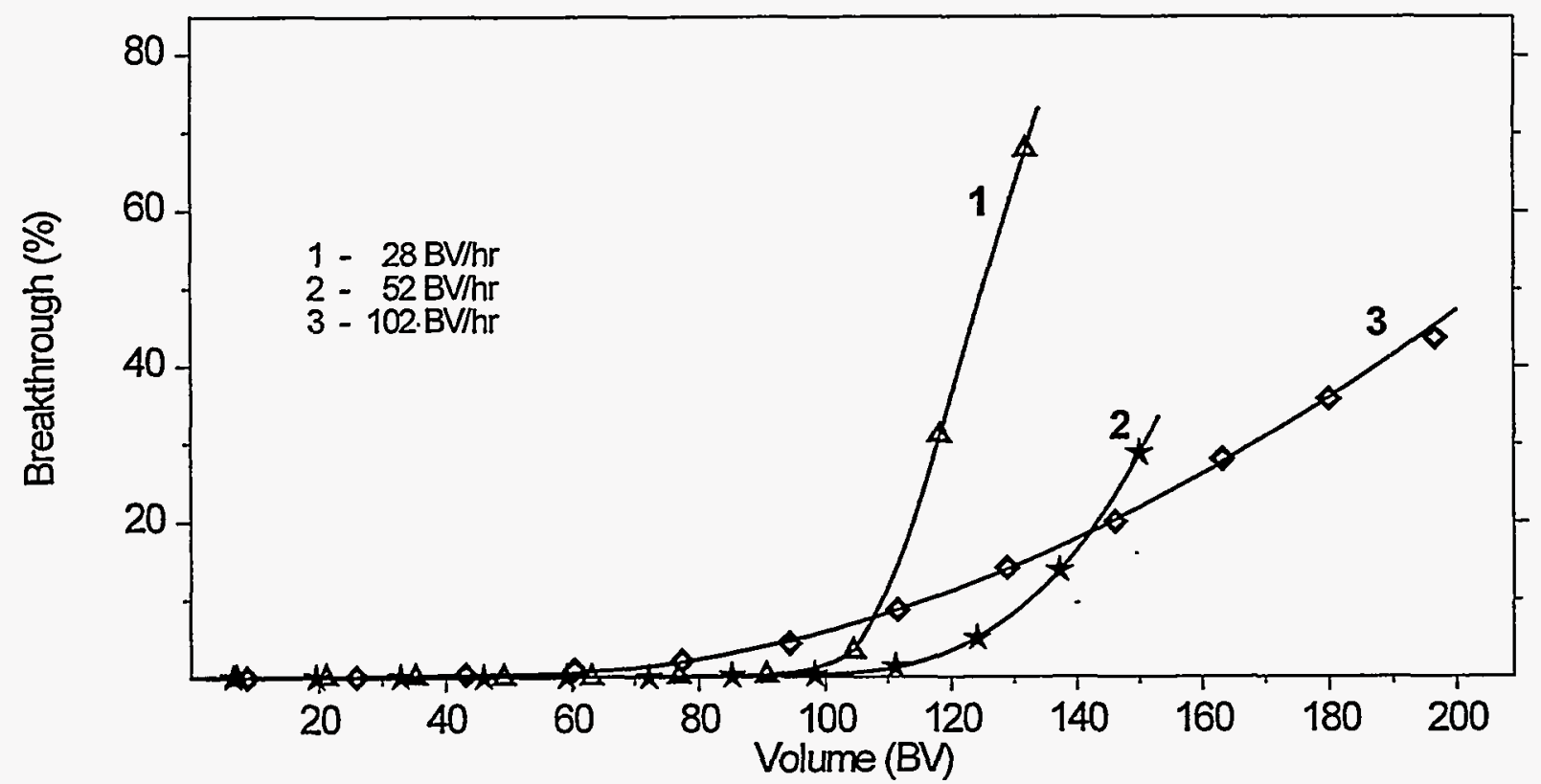

Figure 5. Influence of the flow rate on the breakthrough of ${ }^{137} \mathrm{Cs}$ through a column of KCoFC-PAN absorber. Grain size $0.3-0.63 \mathrm{~mm} ; 0.1 \mathrm{MNaOH}+1 M \mathrm{NaNO}_{3}$; $2 \times 10^{-4} \mathrm{M} \mathrm{CsCl}$. 


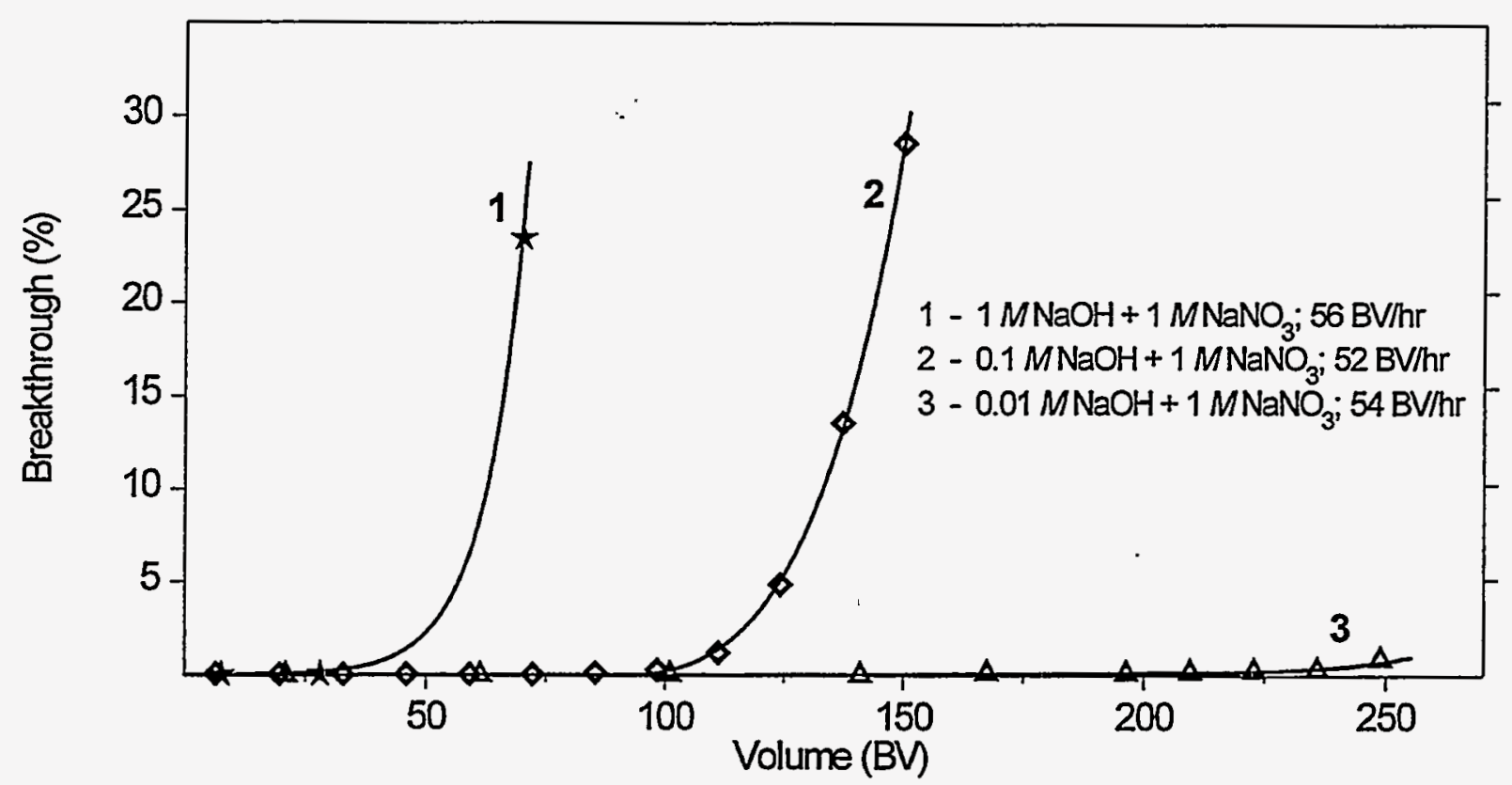

Figure 6. Influence of $\mathrm{NaOH}$ concentration on the breakthrough of ${ }^{137} \mathrm{Cs}$ from $1 \mathrm{MNaNO}_{3}$ through a column of KCoFC-PAN absorber. Grain size $0.3-0.63 \mathrm{~mm} ; 2 \times 10^{-4} \mathrm{M}$ $\mathrm{CsCl}$.

Table 4. Influence of $\mathrm{NaOH}$ Concentration on the Breakthrough of Cesium from $1 M \mathrm{NaNO}_{3}$ $+2 \times 10^{-4} \mathrm{M} \mathrm{CsCl}$ Solution at a Flow rate of $\sim 54 \mathrm{BV} / \mathrm{hr}$. Grain size $0.3-0.63 \mathrm{~mm} ; \mathrm{KCoFC}-$

PAN Composite Absorber

\begin{tabular}{|c|c|c|c|}
\hline \multirow{2}{*}{$\begin{array}{c}\text { Breakthrough } \\
(\%)\end{array}$} & \multicolumn{3}{|c|}{ Volume of Feed Solution (BV) } \\
\cline { 2 - 4 } & $\mathbf{1} \boldsymbol{M} \mathbf{~ N a O H}$ & $\mathbf{0 . 1} \boldsymbol{M} \mathbf{~ N a O H}$ & $\mathbf{0 . 0 1} \boldsymbol{M}$ NaOH \\
\hline 0.1 & 30 & 75 & 160 \\
\hline 1 & 40 & 100 & 250 \\
\hline
\end{tabular}

In $0.01 M \mathrm{NaOH}+1 M \mathrm{NaNO}_{3}$ solution, the decomposition of the active component is low. Thus the efficiency of cesium separation from this solution is comparable to that found for cesium separation from acidic simulant solutions (compare Figure 2 with Figure 6, curve 3, or the data in Table 4 with data from Section 3.2.2, while accounting for the order-of-magnitude higher concentration of cesium carrier in the alkaline simulant solutions). Based on these results, the uptake of cesium from solutions with $\mathrm{NaOH}$ concentrations less than 0.01 mole/ $/ \mathrm{L}$ has not been measured. 


\subsection{Elution of Cesium and/or Regeneration of the Absorbers}

\subsubsection{AMP-PAN Absorber}

Cesium is sorbed by ammonium molybdophosphate very selectively; it can be eluted with good efficiency only by concentrated solutions of ammonium salts. ${ }^{19}$ This possibility has already been verified for the AMP-PAN composite absorber. ${ }^{20}$ In a study of AMP-PAN absorber properties, Šebesta and Štefula found that the sorbed cesium can be eluted almost quantitatively. ${ }^{20}$ The regenerated AMP-PAN absorber from which the cesium has been eluted should be reusable in another sorption cycle.

The possibility of regenerating and reusing the AMP-PAN composite absorber when separating cesium from $1 M \mathrm{HNO}_{3}+1 \mathrm{MNaNO}$ was verified during measurement of the cesium breakthrough curve at a flow rate of $114 \mathrm{BV} / \mathrm{hr}$ (see Figure 1, curve 3). The results of cesium elution by $5 \mathrm{M} \mathrm{NH} 4 \mathrm{Cl}+0.1 \mathrm{M} \mathrm{HCl}$ solution are shown in Figure 7, part $\mathrm{A}$. This bar chart shows that $\sim 85 \%$ of cesium is removed by an elution-solution volume that is four times the volume of the absorber bed ( $4 \mathrm{BV}$ ). The remainder of the cesium can be eluted by an additional $\sim 8 \mathrm{BV}$ of the elution solution.

The bed of the AMP-PAN regenerated in this way was used for a new sorption cycle of cesium from $1 M \mathrm{HNO}_{3}+1 M \mathrm{NaNO}_{3}$ solution. The breakthrough curve measured for the regenerated absorber is shown in Figure 8; the corresponding curve measured for the "fresh" nonregenerated absorber is given for comparison. These results show that the efficiency of the regenerated absorber is significantly lower. The breakthrough of cesium exceeded $0.1 \%$ from the beginning of the experiment. With regenerated absorber, the breakthrough of cesium exceeded $1 \%$ after the volume of feed solution reached only $\sim 100 \mathrm{BV}$, which is much less than the $\sim 600 \mathrm{BV}$ found for the fresh absorber.

The most probable reason for the deterioration of sorption properties in the regenerated AMP-PAN composite absorber is the partial dissolution of the ammonium molybdophosphate active component, which was discussed in Section 3.2.1. The solubility of AMP is known to be low but not negligible. The volume of the $1 M \mathrm{HNO}_{3}+1 M \mathrm{NaNO}_{3}$ feed solution treated in the first sorption cycle $(7-8 \mathrm{~L})$ was rather large: note that the $10-\mathrm{mL}$ bed of fresh absorber originally contained only $2.38 \mathrm{~g}$ of AMP in the $9.25 \mathrm{~g}$ bed of AMP-PAN composite absorber (see Table 1 and the "apparent swelling" data).

Another possibility for eluting the cesium sorbed onto the AMP is to decompose the AMP in alkaline media, where the heteropolyanion decomposes. Two examples of this method of cesium elution from the AMP-PAN composite absorber (by $0.1 \mathrm{MNaOH}$ or $1 M \mathrm{NH}_{4} \mathrm{OH}$ ) are shown in Figure 7, parts B and C. By both these agents, cesium can be recovered with an elution-agent volume equal to $4 \mathrm{BV}$. In this case, only the polyacrylonitrile binding polymer is left in the column after the AMP is dissolved as soluble molybdate and phosphates. This method of AMP decomposition was also used earlier for cesium recovery. ${ }^{19}$ 


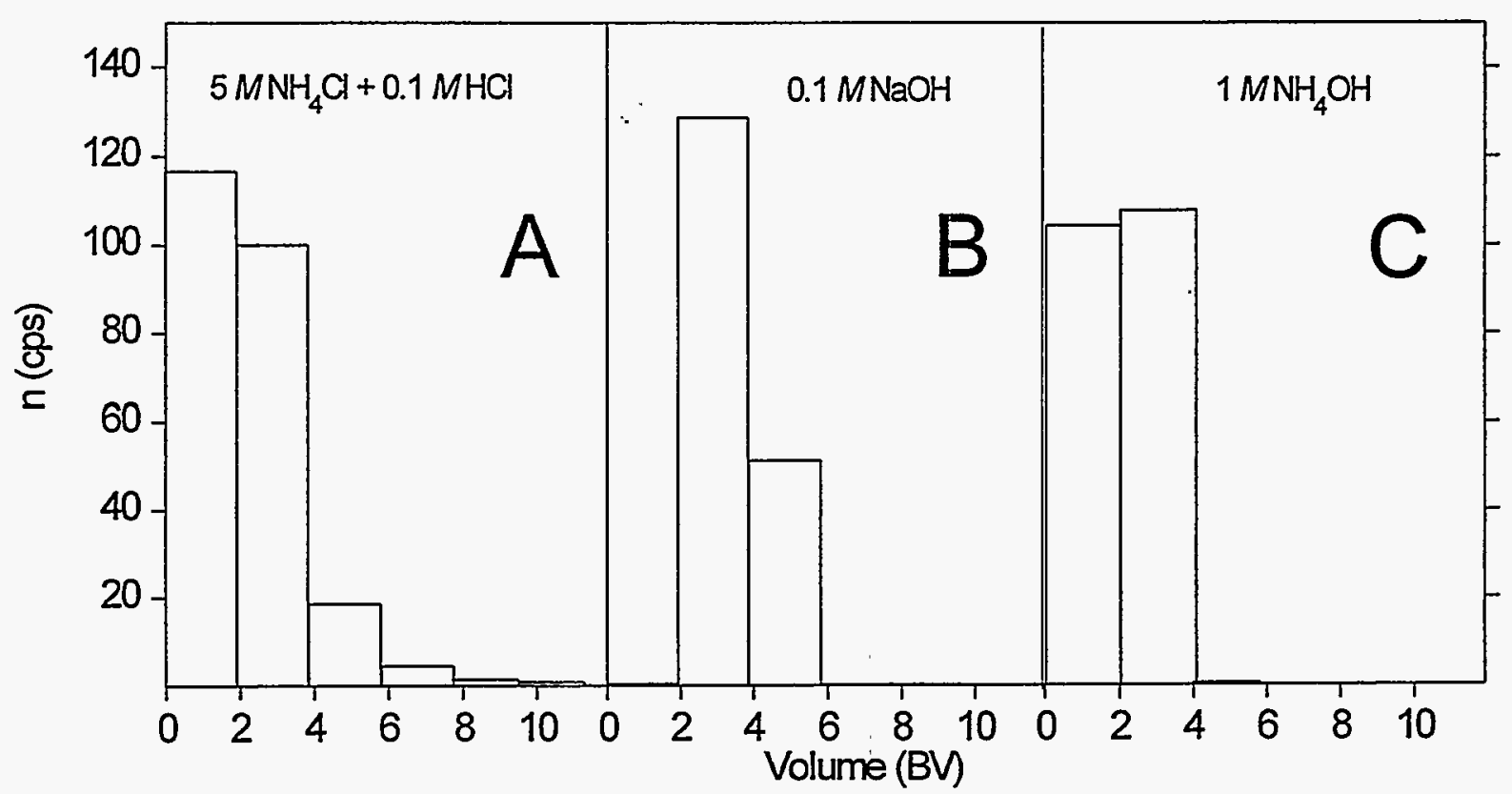

Figure 7. Elution of ${ }^{137} \mathrm{Cs}$ from a column of AMP-PAN absorber by various elution agents. Grain size $0.3-0.7 \mathrm{~mm} ; \mathrm{BV}=10 \mathrm{~mL}$; flow rate $3 \mathrm{BV} / \mathrm{hr}$.

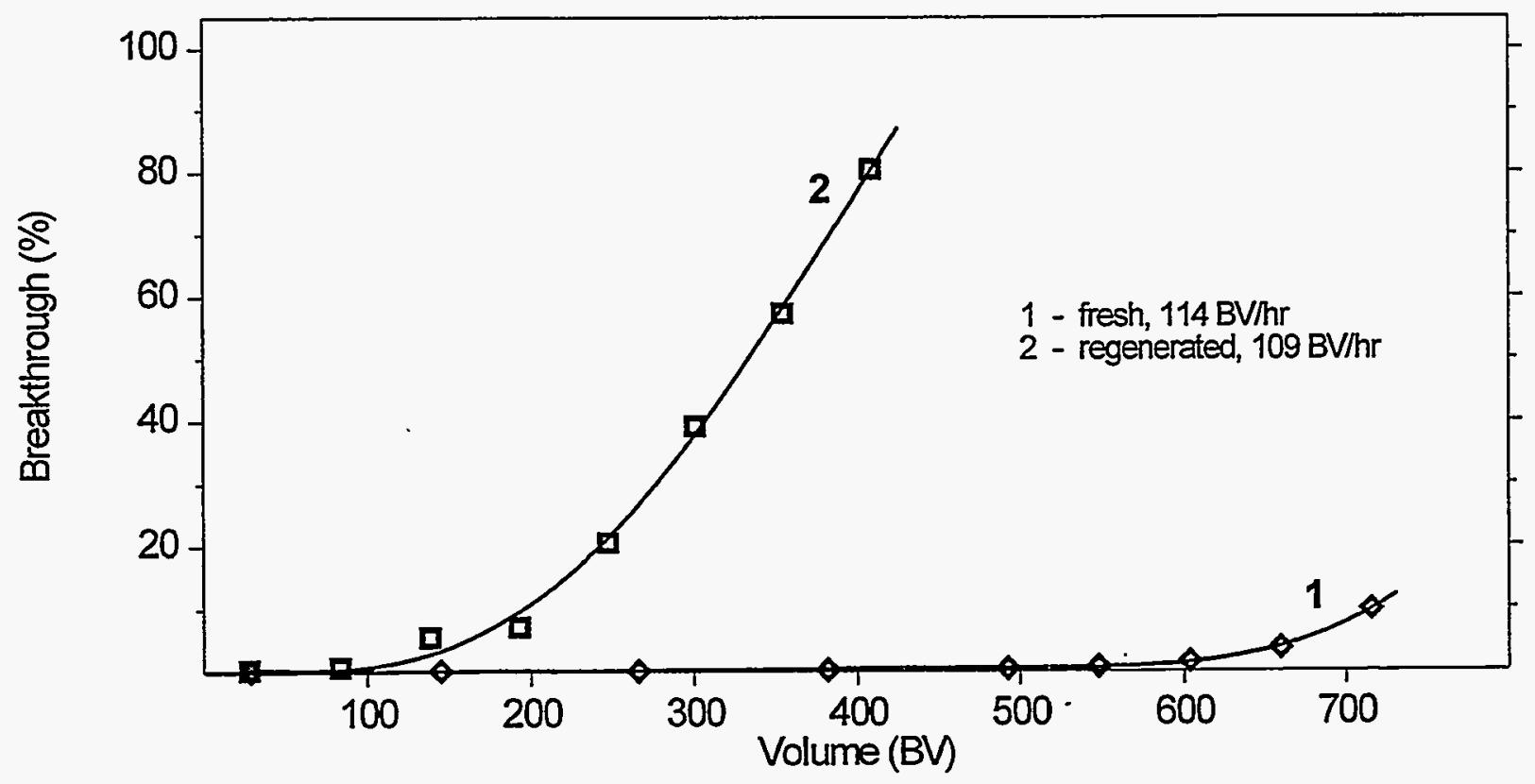

Figure 8. Comparison of the breakthrough of ${ }^{137} \mathrm{Cs}$ through columns of fresh (1) and regenerated (2) AMP-PAN absorbers. Grain size $0.3-0.7 \mathrm{~mm} ; 1 \mathrm{MHNO}_{3}+$ $1 \mathrm{MNaNO}_{3} ; 2 \times 10^{-5} \mathrm{M} \mathrm{CsCl}$. 


\subsubsection{KCoFC-PAN Absorber}

The problem of eluting cesium from solid ferrocyanides and its potential regeneration for repetitive use has not yet been solved. From a critical review of available literature, Haas concluded that "all uses of ferrocyanide solids to remove cesium from solution must be based on one cycle with complete replacement of the cesium-loaded solids." ${ }^{\text {"18 }}$ However, a new separation process (RECS process) proposed by Tanihara ${ }^{21}$ uses copper(II)-type ferrocyanide as a redox exchanger for cesium recovery. The same principle was independently proposed and described by Filipov for cesium recovery from high-level liquid radioactive wastes. ${ }^{22}$ In his study, potassium-copper ferrocyanide on silica was used as an inorganic absorber.

The following conclusions were drawn from very recent published data and our own experience with ferrocyanide-type absorbers:

- Any elution of cesium from metal ferrocyanide solids may be accomplished only by changing their chemical composition, not by classical ion-exchange mechanisms.

- During elution of cesium by solutions of $\mathrm{Hg}\left(\mathrm{NO}_{3}\right)_{2}, \mathrm{TINO}_{3}$, or $\mathrm{AgNO}_{3}$, metal ferrocyanides are irreversibly decomposed. ${ }^{10,23}$ No recycling of the absorber is possible in this case.

- Elution of cesium by concentrated solutions of nitric acid is a consequence of the oxidation of metal ferrocyanides to ferricyanides. ${ }^{21}$ After the elution step, the oxidized absorber may be reconditioned (reduced back to ferrocyanide) for reuse.

- In both cases the elution yield is influenced by the type of metal ferrocyanide, its chemical composition, pretreatment, and physicochemical properties (grain size, deposition on a carrier, etc.).

Potassium-cobalt ferrocyanide $(\mathrm{KCoFC})$ prepared according to Prout et al. ${ }^{10,11}$ involves a thermal pretreatment not suitable for subsequent cesium elution, when prepared in granular form. The presence of finely powdered KCoFC (grain size $<0.1 \mathrm{~mm}$ ) in the KCoFC-PAN composite absorber might be advantageous for either of the above two methods of cesium elution, which is the reason for performing simple scouting experiments to wash cesium out of the KCoFC-PAN absorber. Columns of KCoFC-PAN absorber loaded by cesium during determination of sorption capacity were used for these experiments.

A solution of $\mathrm{AgNO}_{3}$ was used to elute cesium from the column by decomposing the potassium-cobalt ferrocyanide. This elutriant was selected because it was earlier found to elute more than $99 \%$ of cesium from a nickel hexacyanoferrate-based composite absorber (NiFC-PAN). ${ }^{24}$ Figure 9 (curve 1) illustrates that the elution of cesium from KCoFC-PAN composite absorber is more difficult. Washing the column with $~ 8 \mathrm{BV}$ of $1 \mathrm{M} \mathrm{AgNO}_{3}$ solution eluted somewhat more than $90 \%$ of the cesium; further elution occurs very slowly. From measurement of the ${ }^{137} \mathrm{Cs}$ activity of the composite absorber, we concluded that $~ 95 \%$ of cesium was removed in $\sim 20 \mathrm{BV}$ of the elution solution, with $\sim 5 \%$ remaining in the absorber bed. 


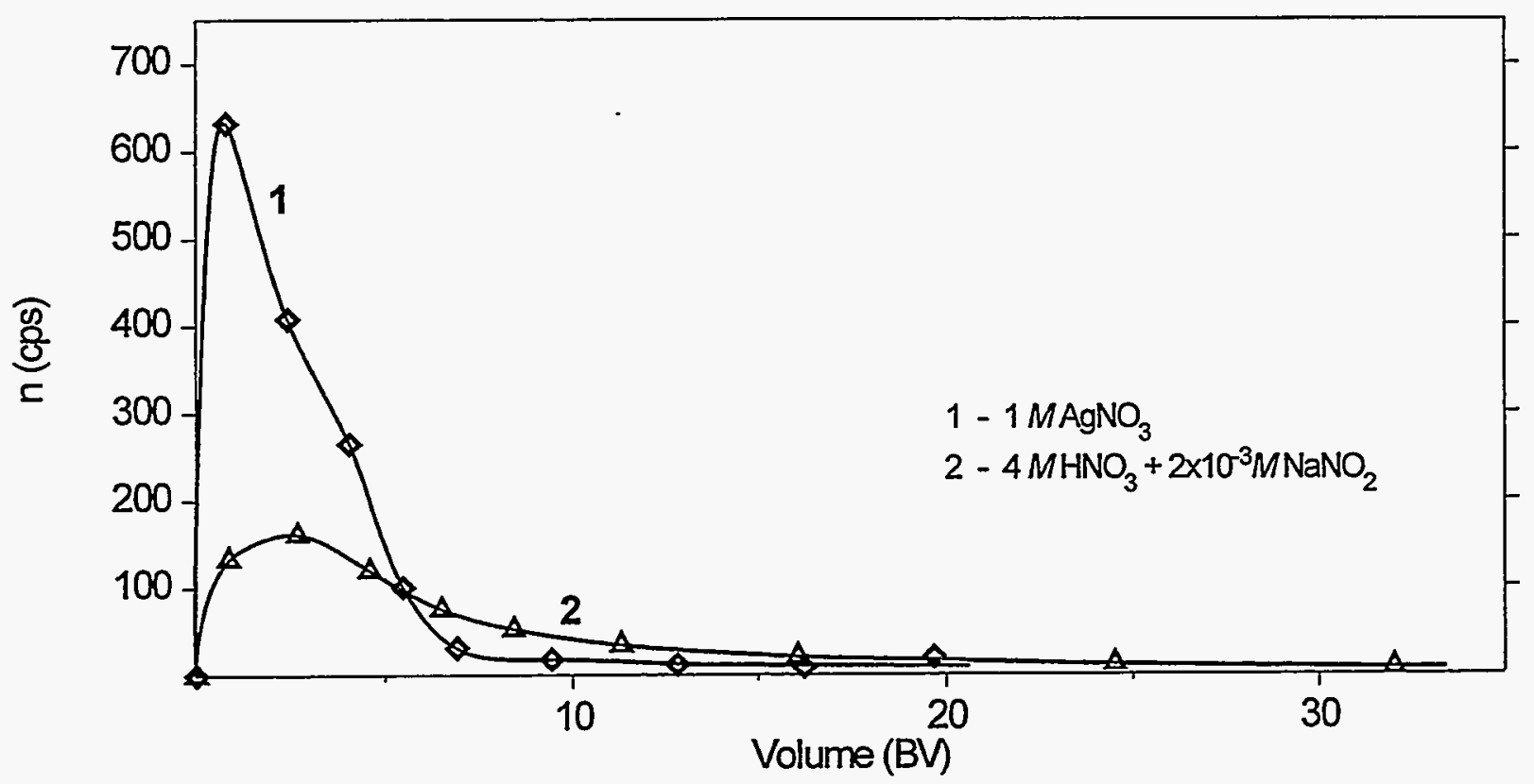

Figure 9. Elution of ${ }^{137} \mathrm{Cs}$ from a column of $\mathrm{KCoFC}-\mathrm{PAN}$ absorber by various elution agents. Grain size $0.3-0.63 \mathrm{~mm} ; \mathrm{BV}=1.8 \mathrm{~mL}$; flow rate $6.6 \mathrm{BV} / \mathrm{hr}$.

A $4 M \mathrm{HNO}_{3}+2 \times 10^{-3} \mathrm{M} \mathrm{NaNO}_{2}$ solution was chosen for eluting cesium from the column by oxidizing ferrocyanide to ferricyanide, based on the general data given by Tanihara. ${ }^{21,25}$ No optimization of the solution composition (concentration adjustment) was attempted. The measured elution curve is shown in Figure 9 (curve 2). From the balance of ${ }^{137} \mathrm{Cs}$ activity sorbed onto and eluted from the column, we concluded that only $\sim 50 \%$ of cesium was recovered. The elution yield could not be significantly improved even by contacting the absorber with the elution agent for several days.

Even though the elution of cesium from KCoFC-PAN absorber by oxidation of the absorber was not quantitative, the possibility of regenerating and recycling the absorber was tested. After eluting cesium, the absorber was reconditioned (reducing the ferricyanide back to ferrocyanide)

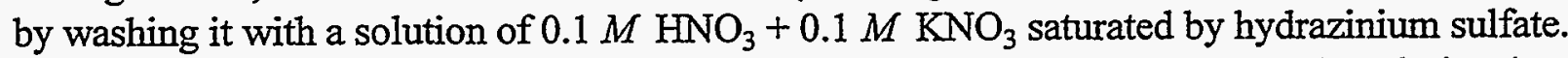
After flushing the bed of the regenerated absorber with $1 M \mathrm{HNO}_{3}+1 M \mathrm{NaNO}_{3}$ solution (as described in Section 2.3.4.), its sorption capacity was determined to be $\sim 55 \%$ of the original sorption capacity of fresh KCoFC-PAN (see Table 2).

This experiment confirmed that part of the cesium can be eluted from the KCoFC-PAN composite absorber. The portion of the absorber from which cesium could be eluted also can be regenerated without any loss of the absorber capacity. For practical application, the elution procedure would need optimization (e.g., acid concentration) because the composition of the elution solution is probably not ideal. Because no elution/regeneration/recycling experiments were originally planned, a more detailed study of this process was not conducted. 


\subsection{CONCLUSIONS}

The performance of PAN-based composite absorbers for the treatment of DOE liquid radioactive wastes was evaluated with acidic and alkaline simulant solutions. AMP-PAN and KCoFCPAN composite absorbers (with ammonium molybdophosphate and potassium-cobalt ferrocyanide active components, respectively) were used for separating cesium from $1 M \mathrm{HNO}_{3}+1 \mathrm{M}$ $\mathrm{NaNO}_{3}+2 \times 10^{-5} M \mathrm{CsCl}$ acidic simulant solution. KCoFC-PAN and two other ferrocyanidebased composite absorbers were used for separating cesium from alkaline simulant solutions containing $0.01 \mathrm{M}$ to $1 \mathrm{M} \mathrm{NaOH}$ and $1 \mathrm{MNaNO}_{3}+2 \times 10^{-4} \mathrm{M} \mathrm{CsCl}$. The tested absorbers contained the same amount of the respective active component $(85.7 \% \mathrm{w} / \mathrm{dry}$ weight). The efficiency of cesium removal was evaluated at flow rates ranging from 25 to $100 \mathrm{BV}$ per hour.

A comparison of AMP-PAN and KCoFC-PAN sorption capacities for cesium in $1 \mathrm{MHNO}_{3}+$ $1 \mathrm{MNaNO}_{3}+0.025 \mathrm{M} \mathrm{CsCl}$ revealed that the sorption capacity of the KCoFC-PAN absorber is $17 \%$ higher than that of AMP-PAN (if expressed per volume of the absorber). This difference may be ascribed to the difference in the sorption capacities of the active components used to prepare the composite absorbers: 0.82 and $0.45 \mathrm{mmole} / \mathrm{g}$ for the $\mathrm{KCoFC}$ and AMP active components, respectively.

The efficiency of cesium separation on the AMP-PAN composite absorber from acidic simulant solutions was negatively influenced by the dissolution of the AMP active component. This fact, together with the rapid kinetics of cesium uptake, accounted for the improved results obtained at higher feed flow rates. A breakthrough below $0.1 \%$ was achieved at all the flow rates tested. At flow rates of $\sim 50 \mathrm{BV} / \mathrm{hr}$, the lowest decontamination factor $\left(D_{f} \sim 10^{3}\right)$ can be maintained for the largest volume of the feed $(\sim 380 \mathrm{BV})$.

The efficiency of cesium separation on the KCoFC-PAN composite absorber from acidic simulant solutions was found to be much better than on the AMP-PAN absorber. Cesium separation was not visibly influenced by the decomposition and/or dissolution of the $\mathrm{KCoFC}$ active component, even though coloration changes of the effluent solution (relative to the feed) were observed. The measured breakthrough curves corroborated the anticipated better efficiency of cesium uptake by the $\mathrm{KCoFC}-\mathrm{PAN}$ at lower flow rates. At a flow rate of $\sim 50 \mathrm{BV} / \mathrm{hr}$, the decontamination factor $D_{f} \sim 10^{3}$ could be maintained for a feed volume as high as $1800 \mathrm{BV}$.

The efficiencies of KCoFC-PAN, CoFC-PAN, and NiFC-PAN composite absorbers for separating cesium from $1 M \mathrm{NaOH}+1 \mathrm{MNaNO}_{3}+2 \times 10^{-4} \mathrm{M} \mathrm{CsCl}$ were compared at a flow rate of $\sim 30 \mathrm{BV} / \mathrm{hr}$. For these absorbers, coloration changes of the effluent solutions indicated decomposition of the active components. A study of the influence of flow rate on cesium uptake by the KCoFC-PAN absorber revealed that the decomposition of the active component cannot be compensated for (even partially, similar to the case of the AMP-PAN composite absorber) by applying higher flow rates. At a flow rate of $\sim 100 \mathrm{BV} / \mathrm{hr}$, the breakthrough exceeded $1 \%$ from the start of the experiment, increasing rapidly.

The influence of the feed-flow rate on the uptake of cesium by the KCoFC-PAN absorber was studied in more detail at a decreased sodium hydroxide concentration of $0.1 \mathrm{~mole} / \mathrm{L}$, where higher stability of the active component could be expected. The optimum flow rate for cesium removal was found to be $50 \mathrm{BV} / \mathrm{hr}$. At this rate, the influence of the sodium hydroxide concentration on the cesium uptake by the KCoFC-PAN absorber from alkaline simulant solutions was 
studied. The breakthrough of cesium from a solution of $1 \mathrm{M} \mathrm{NaNO}_{3}$ containing $2 \times 10^{-4} \mathrm{M} \mathrm{CsCl}$ exceeded the $0.1 \%$ threshold after $30 \mathrm{BV}, 75 \mathrm{BV}$, and $160 \mathrm{BV}$ of alkaline simulant solutions with sodium hydroxide concentrations of $1 \mathrm{~mole} / \mathrm{L}, 0.1 \mathrm{~mole} / \mathrm{L}$, and $0.01 \mathrm{~mole} / \mathrm{L}$, respectively. The efficiency of cesium separation from the solution containing $0.01 \mathrm{M} \mathrm{NaOH}$ is comparable to that found for cesium separation from acidic simulant solutions if the tenfold higher concentration of cesium carrier in the alkaline simulant solutions is accounted for. This finding indicates that the decomposition (if any) of the absorber during the course of the experiment is low.

Limited experiments confirmed that cesium may be eluted from both the AMP-PAN and the KCoFC-PAN cesium-loaded composite absorbers after the decomposition of the respective active components. Cesium can be removed practically quantitatively from the AMP-PAN absorber in $\sim 4 \mathrm{BV}$ of either $1 \mathrm{M} \mathrm{NH}_{4} \mathrm{OH}$ or $0.1 \mathrm{M} \mathrm{NaOH}$. The elution of cesium from the KCoFC-PAN absorber is more complicated. Although more than $90 \%$ of the cesium could be eluted in $\sim 8 \mathrm{BV}$

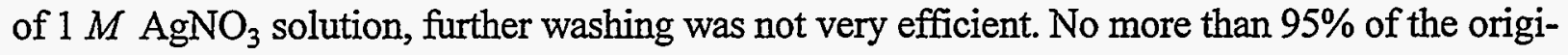
nally sorbed cesium could be eluted.

Regeneration of AMP-PAN absorber can be accomplished by eluting cesium with concentrated solutions of ammonium salts (e.g., $5 \mathrm{M} \mathrm{NH}_{4} \mathrm{Cl}$ ). Unfortunately, the solubility of the AMP active component rapidly decreases the practical sorption capacity of the absorber. Therefore regeneration of this absorber cannot be considered for treatment of large volumes of liquid radioactive wastes, unless the solubility of the active component can be decreased by modifying the procedure for preparation of the active component and/or the composite absorber.

Limited experiments confirmed that even the ferrocyanide-based composite absorbers may be considered for regeneration and reuse. Their regeneration requires elution of cesium by oxidizing the ferrocyanide to ferricyanide and reconditioning the absorber by reducing it back to ferrocyanide. The KCoFC-PAN composite absorber was regenerated by $~ 50 \%$ in the scouting experiments while fully maintaining its sorption capacity. 


\subsection{SUMMARY OF PROJECT RESULTS}

The most significant result of the project is the demonstration that polyacrylonitrile is a versatile polymer capable of forming porous composite absorbers with small particles of numerous primary absorbers. These composite absorbers were shown to be capable of withstanding specified acidic and alkaline conditions and significant radiation doses that may be encountered when treating DOE liquid radioactive wastes.

PAN binder may be used to prepare composite absorbers for treating acid wastes and alkaline solutions with $\mathrm{pH}$ up to 14 . In most cases, the potential application of PAN-based composite absorbers will be dependent on the primary absorber and not limited by the stability of the PAN binder.

\subsection{Phase I Results}

In acidic solutions, the stability of polyacrylonitrile binder is not limited by either chemical or radiation decomposition (within the range of conditions studied). The study of the chemical stability of PAN in the form of macroporous beads (B-PAN), similar to the beads of composite absorbers, demonstrated their excellent chemical stability during 1 month of contact with $1 \mathrm{M}$ $\mathrm{HNO}_{3}+1 \mathrm{M} \mathrm{NaNO}_{3}$. The chemical stability of AMP-PAN composite absorber (ammonium molybdophosphate active component in PAN binder) was found to be as good as that of B-PAN beads. No changes of sorption properties $\left(K_{D}\right.$-values, sorption capacity, or kinetics of cesium uptake) of the AMP-PAN composite absorber were observed within the testing period.

In highly alkaline solutions ( $\mathrm{NaOH}$ concentrations $<1 \mathrm{~mole} / \mathrm{L}$ ) and in the presence of $\mathrm{NaNO}_{3}$, the stability of the tested polyacrylonitrile polymer was sufficient for applications of composite absorber up to 10 days. The experimental results proved that the hydrolysis of PAN is accelerated by the presence of sodium nitrate. Our study of the influence of sodium hydroxide concentration on the chemical stability of the binder revealed that in $0.1 M \mathrm{NaOH}+1 M \mathrm{NaNO}_{3}$, PAN is stable for 1 month. Because of high sorption rates achievable with these absorbers, the sorption capacity of practically any active component will be usually exhausted before significant decomposition of the binder. The stability is thus sufficient for most applications in the DOE complex.

The radiation stability of the PAN binder was found to be satisfactory to radiation doses of $10^{6} \mathrm{~Gy}\left(10^{8} \mathrm{rad}\right)$ for all the media tested (distilled water, $1 M \mathrm{HNO}_{3}+1 M \mathrm{NaNO}_{3}, 1 \mathrm{MNaOH}$, and $1 M \mathrm{NaOH}+1 M \mathrm{NaNO}_{3}$ ). In alkaline simulant solutions, the positive influence of $\gamma$-radiation on the chemical stability of PAN in alkaline media was clearly seen. This effect was unambiguously ascribed to $\mathrm{PAN}$ polymer cross-linking during irradiation, manifesting itself in higher resistance of the polymer to hydrolysis. This effect enables the period of applicability of PAN-based composite absorbers to be extended. Further improvements in the chemical stability of the binding polymer might be achieved by selecting another type of polymer from the broad family of $P A N$ polymers.

\subsection{Phase II Results}

The efficiency of cesium separation on the column of AMP-PAN composite absorber (ammonium molybdophosphate active component) from $1 M \mathrm{HNO}_{3}+1 M \mathrm{NaNO}_{3}+2 \times 10^{-5} \mathrm{M}$ $\mathrm{CsCl}$ acidic simulant solution was negatively influenced by the dissolution of the AMP active 
component. Nevertheless, good results were obtained at higher flow rates $(50-100 \mathrm{BV} / \mathrm{hr})$. At flow rates of $\sim 50 \mathrm{BV} / \mathrm{hr}$, the decontamination factor $D_{f} \sim 10^{3}$ could be maintained for treatment of $\sim 380 \mathrm{BV}$ of feed. The breakthrough curves measured on the KCoFC-PAN composite absorber (potassium-cobalt ferrocyanide active component) corroborated the anticipated better efficiency of cesium uptake by the KCoFC-PAN absorber at lower flow rates. At a flow rate of $\sim 50 \mathrm{BV} / \mathrm{hr}$, the decontamination factor $D_{f} \sim 10^{3}$ could be maintained to $1800 \mathrm{BV}$ of feed.

For the alkaline simulant solutions, the efficiency of KCoFC-PAN, CoFC-PAN, and NiFCPAN composite absorbers for separating cesium from $1 \mathrm{M} \mathrm{NaOH}+1 \mathrm{MNaNO}_{3}+2 \times 10^{-4} \mathrm{M}$ $\mathrm{CsCl}$ was compared at a flow rate of $\sim 30 \mathrm{BV} / \mathrm{hr}$. Although the best performance was exhibited by the KCoFC-PAN composite absorber, significant decomposition of all absorbers was observed. Our study of the influence of flow rate on cesium uptake by KCoFC-PAN revealed that the decomposition of the active component cannot be compensated for (even partially, similar to AMP-PAN) by applying higher flow rates.

A flow rate of $50 \mathrm{BV} / \mathrm{hr}$ was found to be efficient for cesium sorption on the KCoFC-PAN absorber from a sodium hydroxide concentration of $0.1 \mathrm{~mole} / \mathrm{L}$. At this flow rate, the influence of the sodium hydroxide concentration on cesium uptake by the KCoFC-PAN absorber from alkaline simulant solutions containing $1 \mathrm{M} \mathrm{NaNO}_{3}+2 \times 10^{-4} \mathrm{M} \mathrm{CsCl}$ was studied. The efficiency of cesium sorption from the solution containing $0.01 \mathrm{M} \mathrm{NaOH}$ was found to be comparable to that found for cesium sorption from acidic simulant solutions. At higher sodium hydroxide concentrations, cesium breakthrough occurred significantly earlier because of absorber decomposition.

Limited experiments confirmed that cesium can be eluted from both the AMP-PAN and the KCoFC-PAN cesium-loaded composite absorbers. After decomposition of the absorbers, cesium can be eluted practically quantitatively from the AMP-PAN in $\sim 4 \mathrm{BV}$ of either $1 \mathrm{M} \mathrm{NH}_{4} \mathrm{OH}$ or $0.1 M \mathrm{NaOH}$, whereas more than $90 \%$ of cesium can be eluted from the KCoFC-PAN in $~ 8 \mathrm{BV}$ of $1 \mathrm{M} \mathrm{AgNO}_{3}$.

Regeneration of both the AMP-PAN and KCoFC-PAN absorbers for reuse was shown to be possible. Because of the solubility of the AMP active component, regeneration of this absorber cannot be considered for treating large volumes of liquid radioactive wastes unless the solubility of the active component can be decreased by modifying the procedure for preparation of the active component and/or the composite absorber. In scouting experiments, the KCoFC-PAN composite absorber was regenerated by $\sim 50 \%$ while fully maintaining its sorption capacity. 


\subsection{RECOMMENDATIONS}

Recommendations for future studies to evaluate PAN as a binding polymer for absorbers used to treat liquid radioactive wastes are based on the results obtained from both Phase I and Phase II of this project. The primary conclusion of this project is that more attention should be given to finding active components of the composite absorbers that are stable and efficient enough to withstand the harsh conditions of the expected DOE waste solutions.

Our recommendations can be divided into two groups. The first is a summary of some general problems and/or areas of research where further study might contribute significantly to better knowledge of the properties of polyacrylonitrile polymer and PAN-based absorbers. Solving these problems would enable more exact evaluation and prediction of the behavior of PAN-based composite absorbers under conditions of potential full-scale applications.

The second group of recommendations summarizes practical measures for obtaining answers to two fundamental questions:

1. Can the PAN-based composite absorbers be applied in actual field conditions for treating actual liquid radioactive wastes at a DOE site?

2. Do the PAN-based composite absorbers offer advantages in any of the major target areas over available materials?

If the answers to these two questions are positive, then the more general problems deserve investigation. An outline of a proposal to resolve the first question rapidly and inexpensively is described below.

A positive response to the second question is indicated in recent reports by Marsh et al., who compared the performance of various absorbers in batch experiments in a variety of realistic simulant solutions of DOE wastes. ${ }^{4-9}$ Nevertheless, a more detailed comparison of the few bestperforming materials should be undertaken under dynamic conditions, if possible. The most obvious performance-comparison experiment involves PAN-based composite absorbers and crystalline silicotitanates, which probably are the most promising absorbers for removing cesium and strontium from acidic and alkaline wastes. We had hoped to perform such a comparison within this project; however, we were unable to obtain the required crystalline silicotitanate material because of export restrictions.

Because both PAN-based absorbers and crystalline silicotitanates are large groups of absorbers, the selection and performance of the tested samples would have to be optimized by the producers, who are well acquainted with the exact composition of the testing solutions. The experimental component of such a test could be performed either at the CTU facilities, as one of the follow-on activities proposed below, or by an independent laboratory (e.g., a DOE national laboratory). In either case, the producers of the absorbers should be involved in the design of test experiments, including the selection of the simulants.

\subsection{General Considerations}

Although some general areas of interest concerning the properties of binding polymers and PAN-based composite absorbers were summarized in the Phase I report, ${ }^{2}$ new proposals have 
resulted from the information derived in this study. Research in this area should consider the following objectives:

- Testing the behavior and stability of B-PAN beads in alkaline media in dynamic experiments simulating actual packed-bed applications.

- Testing the behavior of selected composite absorbers with alkali-resistant active components (e.g., TiO-PAN, ZrP-PAN) in dynamic sorption experiments similar to those described in this report.

- Studying the chemical stability of B-PAN beads in alkaline media after preliminary irradiation of the beads in distilled water.

- Selecting and preparing another polymer from the broad family of PAN polymers that is more suitable for highly alkaline media and testing its properties by the batch experimental methods developed under Phase I research.

- Investigating the possibility of regenerating spent composite absorbers and the influence of such regeneration on their stability and repeated use.

- Identifying target DOE waste types for treatment by PAN-based composite absorbers, selecting prospective active components for radionuclides to be separated, and optimizing the properties of these active components.

- Verifying the proposed explanation for swelling increase and/or mechanism of PAN hydrolysis: formation of carboxylate groups on the polymer skeleton in the course of alkaline hydrolysis.

\subsection{Follow-on Activities}

As noted in the introduction to this chapter, the follow-on activities should concentrate on assessing the applicability of PAN-based composite absorbers to the treatment of actual wastes. The logical next step is to perform a pilot plant demonstration of PAN technology at a DOE site. Because the long-term stability of the PAN binder in highly alkaline media is not yet fully established, we recommend this demonstration be performed with acidic liquid radioactive wastes (e.g., the type stored at Idaho Chemical Processing Plant or another actual acidic waste). Based on experience with earlier demonstrations at the pilot plant scale, cesium isotopes may be proposed as target radionuclides for the demonstration.

The results obtained in Phase II of this project have not fully confirmed the original premise that AMP-PAN composite absorber should be selected for the demonstration of the performance of the binding polymer in actual acidic radioactive wastes. Much more promising results were obtained with composite absorbers with ferrocyanide-based active components, and the possibility exists for cesium elution and the regeneration and reuse of composite ferrocyanide absorbers.

The main objective of any follow-on activities should be a pilot plant demonstration. Also, at least some part of the activities should be directed at solving the more important general problems (from a practical perspective). Thus the following objectives are suggested:

- Test the behavior of some composite absorbers with alkali-resistant active components (e.g. TiO-PAN, crystalline silicotitanates-PAN) in dynamic sorption experiments.

- Develop a binder that is more stable in concentrated alkalis. 
To reach these objectives, a 1-year, two-stage, four-task project is proposed. In the first stage, the following tasks would be performed:

1. Optimization of conditions for an on-site demonstration experiment, including:

(a) final selection of the type of waste and the active component of the composite absorber to be tested, and

(b) optimization of the properties of the selected absorber(s) in both batch and dynamic column experiments with simulant solutions (to be performed at CTU).

2. Development of a binder more stable in concentrated alkalis, including:

(a) identification and acquisition of polymers potentially more stable in concentrated alkalis, and

(b) study of the chemical stability of B-PAN beads in alkaline media after preliminary irradiation in distilled water.

In the second stage, the following tasks would be performed:

1. On-site performance demonstrations of the optimized absorber with actual waste in both batch and dynamic experiments (to be performed at the selected DOE site in collaboration with the local staff).

2. Testing of binders more stable in concentrated alkalis, including

(a) chemical stability tests of materials acquired under Task 2a of the first stage, and

(b) dynamic sorption experiments to remove strontium from alkaline simulant solutions.

As noted in the previous section, another potential task for the proposed program is a comparison of PAN-based absorbers with silicotitanates, either prepared in an engineered form or as a composite in the PAN binding polymer. 


\subsection{REFERENCES}

1. Šebesta, F., J. John, A. Motl, and J. Watson. "Development of PAN-Based Absorbers for Treating Waste Problems at U.S. DOE Facilities." In: Proc. 1995 Int. Conf. Nucl. Wastes Management and Environmental Remediation, Berlin, Germany, September 5-11, 1995, ASME, New York, 1995, Vol. 3, pp.871-878.

2. Šebesta, F., J. John, A. Motl, and K. Štamberg. "Evaluation of Polyacrylonitrile (PAN) as a Binding Polymer for Absorbers Used to Treat Liquid Radioactive Wastes." Phase I Draft Report of Agreement for Services No. FSU/CTU-1 between the Florida State University and the Czech Technical University in Prague, SAND95-2729, November $1995,46 \mathrm{pp}$.

3. Agreement for Services No. FSU/CTU-1 between Florida State University and the Czech Technical University in Prague, Attachment A - Scope of Work, Task 2: Evaluation of Polyacrylonitrile (PAN) as a Binding Polymer for Absorbers Used to Treat Liquid Radioactive Wastes.

4. Marsh, S.F., Z.V. Svitra, and S.M. Bowen. "Distribution of 14 Elements on 63 Absorbers from Three Simulant Solution (Acid-Dissolved Sludge, Acidified Supernate, and Alkaline Supernate) for Hanford Tank 102-SY." LA-12654, Rev., August 1994, 103 pp.

5. Marsh, S.F., Z.V. Svitra., and S.M. Bowen. "Distribution of 15 Elements on 58 Absorbers from Simulated Hanford Double-Shell Slurry Feed (DSSF)." LA-12863, November $1994,50 \mathrm{pp}$.

6. Svitra, Z.V., S.F. Marsh., and S.M. Bowen. "Distribution of 12 Elements on 64 Absorbers from Simulated Hanford Neutralized Current Acid Waste (NCAW).” LA-12889, December 1994, $48 \mathrm{pp}$.

7. Marsh, S.F., Z.V. Svitra, and S.M. Bowen. "Effects of Aqueous-Soluble Organic Compounds on the Removal of Selected Radionuclides from High-Level Waste. Part I: Distribution of $\mathrm{Sr}, \mathrm{Cs}$, and Tc onto 18 Absorbers from an Irradiated, OrganicContaining Leachate Simulant for Hanford Tank 101-SY.” LA-12862, January 1995, $10 \mathrm{pp}$.

8. Marsh, S.F., Z.V. Svitra, and S.M. Bowen. "Effects of Soluble Organic Complexants and Their Degradation Products on the Removal of Selected Radionuclides from HighLevel Waste. Part II: Distributions of Sr, Cs, Tc, and Am onto 32 Absorbers from Four Variations of Hanford Tank 101-SY Simulant Solution." LA-12943, April 1995, 47 pp.

9. Marsh, S.F., Z.V. Svitra, and S.M. Bowen. "Effects of Soluble Organic Complexants and Their Degradation Products on the Removal of Selected Radionuclides from HighLevel Waste. Part III: Distributions of Sr, Cs, Tc, Pu, and Am onto 33 Absorbers from Four Variations of a 3:1 Dilution of Hanford Complexant Concentrate (CC) Simulant Solution. Part IV: The Effects of Varying Dilution Ratios on the Distributions of Sr, $\mathrm{Cs}, \mathrm{Tc}, \mathrm{Pu}$, and Am onto 12 Absorbers from Hanford Complexant Concentrate (CC) Simulant Solution." LA-13000, September 1995, 64 pp.

10. Prout, W.E., E.R. Russell, and H.J. Groh. "Ion Exchange Absorption of Cesium by Potassium Hexacyanocobalt(II) Ferrate(II)." J. Inorg. Nucl. Chem., 27, 1965, pp. 473-479. 
11. Prout, W.E., E.R. Russell, and H.J. Groh. "Removal of Cesium from Aqueous Solutions by Ion Exchange." U.S. Patent 3,296,123, 1967.

12. Integrated Data Base for 1993: U.S. Spent Fuel and Radioactive Waste Inventories, Projections, and Characteristics. DOE/RW-0006, Rev. 9, March 1994, 329 pp.

13. Herbst, R.S., K.N. Brewer, J.D. Law, T.J. Tranter, and T.A. Todd. "TRUEX Partitioning Studies Applied to ICPP Sodium Bearing Waste." In: Proc. SPECTRUM '94, Atlanta, USA, August 14-18, 1994, ANS, LaGrange Park, Il, 1994, Vol. 3, pp. 2257-2262.

14. Folsom, T.R., and C. Sreekumaran. "Some Reference Methods for Determining Radioactive and Natural Caesium for Marine Studies." In: Reference Methods for Marine Radioactivity Studies. Technical Report Series No. 118, IAEA, Vienna, 1970, p. 172

15. Šebesta, F. Unpublished results.

16. Šebesta, F. "Exchanger Composed from an Active Component and a Binding Organic Matrix and the Way of its Production." Czech Patent A.O. 273 369, 1992.

17. Frána, J. "Program SPDEMOS, version 94-10." Institute of Nuclear Physics, Řež (near Prague), Czech Republic, October 1994.

18. Haas, P.A. "A Review of Information on Ferrocyanide Solids for Removal of Cesium from Solutions." Separ. Sci. Technol., 28, 1993, pp.2479-2506.

19. Amphlett, C.B. Inorganic Ion Exchangers. Elsevier, 1964.

20. Šebesta, F., and V. Štefula. "Composite Ion-Exchanger with Ammonium Molybdophosphate and Its Properties." J. Radioanal.Nucl. Chem., Articles, 140, 1990, p.15-21.

21. Tanihara, K. "Influence of Various Additives on the Sorption of Cesium from Strong Nitric Acid Medium on Potassium Cupric Ferrocyanide." J. Radional. Nucl. Chem., Articles, 173, 1993, pp.37-45.

22. Filipov, E.A., E.G. Dzekun, A.K. Nardova, I.V. Mamakin, V.M. Gelis, and V.V. Milyutin. "Application of Crown-Ethers and Ferrocyanide-Based Inorganic Material for Cesium and Strontium Recovery from High-Level Radioactive Wastes." In: Proc. Symp. on Waste Management, Tucson, Arizona, March 1-5, 1992, Vol. 2, 1992, pp.1021-1025.

23. Lehto, J., and S. Haukka. "Silver Uptake by Potassium-Cobalt Hexacyanoferrate(II)." In: Proc. 3rd Int. Conf. Separation of Ionic Solutes, Stará Lesná, Czechoslovakia, December 4-8, 1989.

24. Šebesta, F., A. Motl, J. John, M. Pražský, and J. Binka. "Composite Ion-Exchangers and their Possible Use in Treatment of Low / Intermediate Level Liquid Radioactive Wastes." In: Proc. 1993 Int. Conf. Nucl. Wastes Management and Environmental Remediation, Prague, Czech Republic, September 5-11, 1993, ASME, New York, 1993, Vol. 3, pp.871-878.

25. Tanihara, K. "Additives for the Separation of Cesium from a Strongly Nitric Acid Medium by Insoluble Ferrocyanide Sorbents." J. Radioanal. Nucl. Chem., Letters, 153, 1991, pp.399-408. 


\section{DISTRIBUTION}

David Aloysius

Dames \& Moore International Engineering 3065 Southwestern Blvd.

Suite 202

Orchard Park, NY 14127

Barbara H. Altenberg

Bechtel Corporation

PO Box 193965

San Francisco, CA 94119-3965

James Antizzo

DOE/EM-36/TREV

Germantown, MD 20874

(pouch mail MS A145)

John Appel

TWRS TDPO, B1-40

723 The Parkway

Richland, WA 99352

Beth Armstrong

Pacific Northwest Laboratories

Battelle Blvd.

Richland, WA 99352

Steve Barker

Westinghouse Hanford Co.

PO Box 1970

Richland, WA 99352

G. Scott Barney

Westinghouse Hanford Co.

PO Box 1970, T5-12

Richland, WA 99352

Jimmy Bell

Oak Ridge National Lab

PO Box 2008

Oak Ridge, TN 37831

Ned E. Bibler

Westinghouse SRS

Savannah River Tech Cntr.

Aiken, SC 20800-0000

Dave Bratzel

Westinghouse Hanford Co.

PO Box 1970

Richland, WA 99352
Rich Braun

UOP

777 Old Saw Mill Road

Tarrytown, NY 10591-6799

Lane Bray

Pacific Northwest Laboratories

Battelle Blvd.

Richland, WA 99352

Ken Brewer

MS 5218

Westinghouse Idaho Nuclear Co.

Idaho Falls, ID 83415

Thomas D. Brewer

Pacific Northwest Laboratories

Battelle Blvd.

Richland, WA 99352

Kriston Brooks

Pacific Northwest Laboratory

Battelle Blvd.

Richland, WA 99352

Garrett Brown

Pacific Northwest Laboratory

Battelle Blvd., P7-25

Richland, WA 99352

William C. Burnett

Florida State University

Tallahassee, FL 32310

Steve Burnum

USDOE Richland Operations PO Box 550

Richland, WA. 99352

David O. Campbell

ORNL

102 Windham Road

Oak Ridge, TN 37831

Clark Carlson

Pacific Northwest Laboratory

Battelle Blvd., P7-25

Richland, WA 99352 
Prof. Greg Choppin

Florida State University

Chemistry Department

Tallahassee, FL 32306

Thurman Cooper

Westinghouse Hanford Co.

PO Box 1970, T5-12

Richland, WA 99352

Cal Delegard

Westinghouse Hanford Co.

Box 1970, T6-09

Richland, WA 99352

Harry Dewey

US DOE

Div. of Chem. Sciences

ER-142, MS F240

Washington, DC 20585

Kevin Eager

Westinghouse Hanford Co.

PO Box 1970, H5-27

Richland, WA 99352

E. Zane Egan

Oak Ridge National Laboratory

PO Box 2008

Oak Ridge, TN 37831

Leif Erickson

A5-16, US Dept of Energy

Richland Field Office

P. O. Box 550

Richland, WA 99352

Steve Felton

Lockheed, MS-TAD

980 Kelly Johnson Drive

Las Vegas, NV 89119

Dennis J. Fennelly

UOP Molecular Sieves

307 Fellowship Rd., Suite 207

Mt Laurel, NJ 08054

Teresa Fryberger DOE/EM-532/TREV

Germantown, MD 20874

(pouch mail MS A145)
Frank Graham

Westinghouse S R Co.

Bldg. 773A

Aiken, SC 29803

Scott Herbst

WINCo

P O Box 4000

Idaho Falls, ID 83415

Roy C. Herndon

Institute for Central and Eastern Eurpoean

Cooperative Environmental Research

Florida State University

2035 East Paul Dirac Dr.

Tallahassee FL 32312

Richard C. Hoyt

Westinghouse Hanford $\mathrm{Co}$.

PO Box 1970, H5-38

Richland, WA 99352

Dave Karraker

Westinghouse S R Co.

S R Tech. Cntr., 773H

Aiken, SC 29802

Anthony Kim

Pacific Northwest Laboratory

Battelle Blvd.

Richland, WA 99352

Randy Kirkbride

Westinghouse Hanford Co.

PO Box 1970, H5-27

Richland, WA 99352

John H. Kolts

US DOE

785 DOE Place

Idaho Falls, ID 83415-1118

Dr. J. Korkisch

Institute of Analytical Chemistry

University of Vienna

A-1090 Vienna, Wahringerstrasse 38

AUSTRIA

Bill Kuhn

Pacific Northwest Laboratory

Battelle Blvd.

Richland, WA 99352 
Dean Kurath

Pacific Northwest Laboratory

Battelle Blvd., P7-43

Richland, WA 99352

Kenneth Lang

DOE/EM-36/TREV

Germantown, MD 20874

(pouch mail MS A145)

Dr. Werner Lutze

Univ. of New Mexico

209 Farris Engineering BIdg.

Albuquerque, NM 87131-1341

Phil McGinnis

Oak Ridge National Lab

PO Box 2008

Oak Ridge, TN 37831-6273

George Mellinger

Pacific Northwest Laboratory

Battelle Blvd., KA-78

Richland, WA 99352

John E. Moerlins

Institute for Central and Eastern Eurpoean

Cooperative Environmental Research

Florida State University

2035 East Paul Dirac Dr.

Tallahassee FL 32312

Michael P. Neary

NUS Laboratory

5350 Campbells Run Road

Pittsburgh, PA 15205

Luis Nuñez

Chem. Tech. Division

Argonne National Laboratory

9700 S. Cass Avenue

Argonne, IL 60439-4837

Charles O'Dell

DOE/EM-36/TREV

Germantown, MD 20874

(pouch mail MS A145)

Arlin L. Olson

WINCo

P O Box 4000

Idaho Falls, ID 83415-5219
Ron Orme

Westinghouse Hanford Co.

PO Box 1970, H5-27

Richland, WA 99352

Gautam Pillay

Pacific Northwest Laboratory

Battelle Blvd.

Richland, WA 99352

Dr.Eric Scriven

Reilly Industries, Inc.

1500 S. Tibbs Avenue

Indianapolis, IN 46242-0912

John Sherman

UOP R\&D Center

50 E. Algonquin Road

Des Plaines, IL 60016-5016

James Sloughter

Westinghouse Hanford Co.

PO Box 1970, T6-07

Richland, WA 99352

Jerry L. Straalsund

TWRS TDPO, B1-40

723 The Parkway

Richland, WA 99352

David J. Swanberg

Dames \& Moore

1933 Jadwin Avenue

Suite 145

Richland, WA 99352

Prof. William Tedder

Chemical Engineering

Georgia Inst. of Technology

778 Atlantic Drive

Atlanta, GA 30332-0100

Major Thompson

Westinghouse S R Co.

PO Box 616

Aiken, SC 29803

Terry A. Todd

WINCo

PO Box 4000

Idaho Falls, ID 83415-5218 
Dr.Anthony P. Toste

Chemistry Department

Southwest Missouri St. Univ.

Springfield, MO 65804

John Tseng

DOE/EM-36/TREV

Germantown, MD 20874

(pouch mail MS A145)

Jack Watson

Oak Ridge National Laboratory

PO Box 2008

Oak Ridge, TN 37831

Denny Wynne

DOE/EM-361/TREV

Germantown, MD 20874

(pouch mail MS A145)

\section{Authors}

Ferdinand Šebesta

(10)

Jan John

Alois Motl

Karel Stamberg

Faculty of Nuclear Sciences and Physical

Engineering, Department of Nuclear Chemistry

Czech Technical University in Prague

Břehová 7, CS - 11519

Prague 1, Czech Republic

\section{Sandia Internal}

MS 0720

MS 0734

MS 0734

MS 0734

MS 0709

MS 0709

MS 9018

MS 0899

MS 0619

MS 0100

MS 0761
T.L. Sanders, 6609

L.D. Bustard, 6624

N.E. Brown, 6624

S.F. Marsh, 6624

J.E. Miller, 6212

H.P. Stephens, 6212

Central Technical Files, 8523-2

Technical Library, 4414

Print Media, 12615

Document Processing for

DOE/OSTI, 7613-2

R.V. Matalucci, 5822
(5)

(25) 